\title{
Oxytetracycline Degradation by Heat-Activated Peroxydisulfate and Peroxymonosulfate Oxidation: Optimization by Box-Behnken Design
}

Kubra Ulucan-Altuntas ( $\nabla$ kubra.altuntas@unipd.it )

Yildiz Technical University https://orcid.org/0000-0001-8811-7948

Senem Yazici Guvenc

Yildiz Technical University: Yildiz Teknik Universitesi

Emine Can-Güven

Yildiz Technical University: Yildiz Teknik Universitesi

Fatih Ilhan

Yildiz Technical University: Yildiz Teknik Universitesi

Gamze Varank

Yildiz Technical University: Yildiz Teknik Universitesi

\section{Research Article}

Keywords: Antibiotic, Persulfate Activation, Peroxymonosulfate Activation, Sulfate radicals, Hydroxyl radicals

Posted Date: February 18th, 2021

DOl: https://doi.org/10.21203/rs.3.rs-180620/v1

License: (c) (i) This work is licensed under a Creative Commons Attribution 4.0 International License. Read Full License 
1 Oxytetracycline Degradation by Heat-Activated Peroxydisulfate and Peroxymonosulfate

$5{ }^{1}$ Yildiz Technical University, Faculty of Civil Engineering, Department of Environmental 6 Engineering, Davutpasa, 34220, Istanbul, Turkey

$7 \quad{ }^{2}$ University of Padova, Department of Chemical Sciences, University of Padova, Via Marzolo 1, 835131 Padova, Italy

\section{$10 *$ Corresponding author}

$11 *$ Kubra Ulucan-Altuntas

121 Yildiz Technical University, Faculty of Civil Engineering, Department of Environmental

13 Engineering, Davutpasa, 34220, Istanbul, Turkey

14 email: kulucan@yildiz.edu.tr

$15{ }^{2}$ University of Padova, Department of Chemical Sciences, University of Padova, Via Marzolo 1, 1635131 Padova, Italy

17 Email: kubra.altuntas@unipd.it 


\section{Oxidation: Optimization by Box-Behnken Design}

\section{ABSTRACT}

21 This study investigates the removal of oxytetracycline performed by persulfate (PS) and

22 peroxymonosulfate (PMS) processes. For this purpose, response surface methodology was used to

23 examine the effectiveness of PS and PMS processes under both alkaline and thermal conditions.

24 The effect of four independent variables, which were selected as $\mathrm{pH}, \mathrm{PS} / \mathrm{PMS}$ concentration,

25 temperature, and time, were analyzed in a wide range. The working $\mathrm{pH}$ was between $\mathrm{pH} 3-11$ to

26 compare acidic and alkaline conditions, and the temperature was selected between 30 and $90{ }^{\circ} \mathrm{C}$

27 to evaluate the effect of thermal activation of sulfate radicals for both processes. According to the

28 results of prepared Response Surface Methodology (RSM) models, all four independent variables

29 were determined to be highly significant for both PS and PMS. Especially in the PMS process, the

30 highest PMS concentration was observed to complete degradation of OTC. The conditions for the

31 highest removal were $\mathrm{pH} 9$ and PS/PMS concentration was approximately $4 \mathrm{mM}$ for both

32 processes, while the temperature and required time were $72.9^{\circ} \mathrm{C}$ and $75^{\circ} \mathrm{C}, 26.5$ min and 20 min,

33 for PS and PMS processes, respectively. PS process has higher kinetic constants at all $\mathrm{pH}$ values

34 than the PMS process.

35 Keyword: Antibiotic, Persulfate Activation, Peroxymonosulfate Activation, Sulfate radicals, 36 Hydroxyl radicals

\section{Introduction}

39 With industrialization, environmental pollution has become an important problem for all living

40 beings; especially these effects are observed at the points where the chemicals used end up with 
41 the discharge or release. One of these emerging chemicals is broad-spectrum antibiotics, which are

42 used to treat infections in humans and animals. Oxytetracycline (OTC) is a low-cost prophylactic

43 antibiotic with broad-spectrum activity, one of the tetracycline (TC) group antibiotics. Although it

44 is for humanitarian purposes, it is a pharmaceutical pollutant that is frequently used as a 45 supplement in the breeding of livestock (Lai et al., 2020). It is a recalcitrant pharmaceutical 46 pollutant for biodegradation, showing that it will be abundant in the aquatic environment for many 47 years. OTC, which has been started to be investigated due to its encounter in aquatic environments 48 (lakes, rivers, etc.), remains in nature for a long time due to its persistence and poses a threat to 49 the deterioration of the ecosystem by triggering the formation of antibiotic-resistant bacteria. 50 Therefore, OTC was chosen as the target pollutants to be degraded by persulfate and 51 peroxymonosulfate processes.

52 Due to the ineffectiveness of traditional biological treatment methods, especially advanced 53 oxidation techniques are among the issues that need to be investigated (Cuerda-Correa et al., 2020).

54 Today, many advanced oxidation processes are successfully applied in many treatment facilities 55 (Ulucan-Altuntas and Ilhan, 2018; Basturk et al., 2020; Can-Guven et al., 2020). From this 56 viewpoint, the Fenton process is used as the most common oxidation process (Zhang et al., 2017; 57 Han et al., 2020; Lai et al., 2020), and several authors have reported that ozone (Li et al., 2008), 58 UV (Yan et al., 2020), photocatalytic membrane reactors (Espíndola et al., 2019) are also effective 59 for OTC degradation. Among the studies conducted for the last decade, advanced oxidation 60 processes (AOPs) based on persulfate activation (PS) are one of the promising methods for the 61 treatment of recalcitrant pollutants. When it reacts with hydroxyl radicals, sulfate radicals with a 62 high oxidative ability and longer life than other active species are formed. Persulfate (PS) and 63 peroxymonosulfate (PMS) are the most effective oxidants in the production of sulfate radicals (Li 64 et al., 2020). So far, the use of ultraviolet (Ao et al., 2019; Bi et al., 2020), microwave (Genc et 65 al., 2020), sonication (Cherifi et al., 2019), heat treatment (Can-Guven et al., 2020), and transition 66 metal ions (Malakotian et al., 2019; Bi et al., 2020) in PS and PMS activation has been tried in the 67 removal of recalcitrant contaminants. Compared to the Fenton process, it has the potential to 68 replace Fenton process applications since it is easier to store and transport persulfate than $\mathrm{H}_{2} \mathrm{O}_{2}$.

69 While heat is effective in activating PS and PMS, it can also improve the degradation of the organic 70 compound. The heat activation of PS and PMS occurs by breaking the single bond between the 
oxygens. The equation showing the formation of sulfate radicals by activation of PS and PMS is

72 as follows (Eq.1 and Eq.2):

73

74

75

76

77

78

$$
\mathrm{S}_{2} \mathrm{O}_{8}^{2-} \rightarrow 2 \mathrm{SO}_{4}
$$

$$
\mathrm{HSO}_{5}^{-} \rightarrow \mathrm{SO}_{4} \cdot+\mathrm{HO}
$$

As can be understood from Eq1 and Eq.2, only sulfate radicals are formed in PS activation, while by using PMS, sulfate radical $\left(\mathrm{SO}_{4} \cdot\right)$ and hydroxyl radicals $(\cdot \mathrm{OH})$ can be formed. However, the reaction of water and $\mathrm{SO}_{4}$. radicals to form $\cdot \mathrm{OH}$ radicals is too slow to be significant in most processes, it is stated in the literature that $\mathrm{SO}_{4} \cdot$ radicals transform more quickly into $\cdot \mathrm{OH}$ radicals with the effect of temperature and $\mathrm{pH}$ (Eq.3).

$$
\mathrm{SO}_{4} \cdot+\mathrm{H}_{2} \mathrm{O} \rightarrow \mathrm{SO}_{4}^{2-}+\mathrm{HO} \cdot+\mathrm{H}^{+}
$$

It has been encountered in some studies that $\mathrm{SO}_{4} \cdot$ radicals are effective when $\mathrm{pH}$ is acidic, and hydroxyl radicals are seen in PS activation when $\mathrm{pH}$ is alkaline. Besides, PS can be activated only by adjusting the $\mathrm{pH}$ to alkaline conditions. In this mechanism, the perhydroxyl radicals formed to play an active role in the formation of sulfate radicals (Eq.4 and Eq.5), hydroxyl radicals (Eq. 6), and superoxides (Eq. 5) (Wang and Wang, 2018).

$$
\mathrm{S}_{2} \mathrm{O}_{8}^{2-}+\mathrm{H}_{2} \mathrm{O} \rightarrow 2 \mathrm{SO}_{4}^{2-}+\mathrm{HO}_{2}^{-}+\mathrm{H}^{+}
$$

$$
\mathrm{S}_{2} \mathrm{O}_{8}^{2-}+\mathrm{HO}_{2}^{-} \rightarrow \mathrm{SO}_{4}^{2-}+\mathrm{SO}_{4} \cdot+\mathrm{O}_{2}^{-} \cdot+\mathrm{H}^{+}
$$

Although there are studies conducted with heat and alkaline environment activation of PS, the number of studies with PMS is quite limited. According to the studies, it is also seen that the effect of the inlet $\mathrm{pH}$ changes on the degradation of different pollutants. Some persulfate and peroxymonosulfate processes made in OTC degradation in the literature are shown in Table 1. It is seen in the studies that UV, transition metal activators, and heat treatment are used as activators. Most of the studies have been done with persulfate activation and it is seen that no comparison with peroxymonosulfate has been made. In the persulfate study activated by heat treatment, it was seen that $2 \mathrm{~h}$ time was required for complete mineralization. 
Table 1. Comparison table of previously published studies

\begin{tabular}{|c|c|c|c|}
\hline Activator & Treatment Conditions & Degradation Eff. & Ref \\
\hline $\mathrm{UV}$ and pre-magnetized $\mathrm{Fe}^{0}$ & $\begin{array}{l}\text { OTC Conc. } 0.8 \mathrm{mg} / \mathrm{L} \\
\text { UV Power } 6 \mathrm{~W} / \mathrm{L} \\
\mathrm{Fe} 00.1 \mathrm{mM} \text {, } \\
\text { PS } 0.1 \mathrm{mM} \text {, } \\
\text { pH } 7.3\end{array}$ & $\begin{array}{l}\text { approx. } 99 \% \text { in } 30 \\
\text { min }\end{array}$ & $\begin{array}{l}\text { (Pan et al., } \\
\text { 2019) }\end{array}$ \\
\hline $\begin{array}{l}\text { Copper Sulphate and UV } \\
\text { (solar simulation) }\end{array}$ & $\begin{array}{l}\text { OTC } 0.04 \mathrm{mM} \\
\text { OTC: } \mathrm{Cu}^{2+}: \mathrm{PS}=1: 1.5: 1.75\end{array}$ & $93.5 \%$ in $60 \mathrm{~min}$ & $\begin{array}{l}\text { (Bi et al., } \\
2020)\end{array}$ \\
\hline Thermo activated & $\begin{array}{l}\text { OTC } 0.03 \mathrm{mM} \\
\text { PS: } 2 \mathrm{mM} \\
\text { Temperature } 50^{\circ} \mathrm{C} \\
\text { pH: } 7\end{array}$ & $100 \%$ in $240 \mathrm{~min}$ & $\begin{array}{l}\text { (Ji et al., } \\
\text { 2016) }\end{array}$ \\
\hline $\mathrm{UV} / \mathrm{PS} / \mathrm{Cu} / \mathrm{NaHCO}_{3}$ & $\begin{array}{l}\text { OTC: } 0.01 \mathrm{mM} \text {, } \\
\text { PS: } 1 \mathrm{mM} \\
\mathrm{Cu}: 0.01 \mathrm{mM} \\
\mathrm{NaHCO}_{3}: 6 \mathrm{mM} \\
\mathrm{UV} 80 \mathrm{~mJ} / \mathrm{cm} 2\end{array}$ & approx. 99\% & $\begin{array}{l}\text { (Liu et al., } \\
\text { 2016a) }\end{array}$ \\
\hline $\begin{array}{l}\text { Biochar and Bentonite } \\
\text { supported } \mathrm{Fe}^{0}\end{array}$ & $\begin{array}{l}\text { OTC } 10 \mathrm{mg} / \mathrm{L} \\
\text { PMS: } 0.1 \mathrm{mM} \\
\text { Biochar supported Fe0: } \\
0.5 \mathrm{~g} / \mathrm{L}\end{array}$ & $93 \%$ in $5 \mathrm{~min}$ & $\begin{array}{l}\text { (Li et al., } \\
2020)\end{array}$ \\
\hline Ultrasound $/ \mathrm{Fe}_{3} \mathrm{O}_{4}$ & $\begin{array}{l}\text { Fe3O4: } 0.3 \mathrm{~g} / \mathrm{L} \\
\text { PS: } 4 \mathrm{mM} \\
\text { TC: } 10 \mathrm{mg} / \mathrm{L} \\
\text { pH10 }\end{array}$ & $\begin{array}{l}92.99 \% \text { in } 90 \\
\text { minute }\end{array}$ & $\begin{array}{l}\text { (Malakotian } \\
\text { et al., 2019) }\end{array}$ \\
\hline $\mathrm{Co}_{3} \mathrm{O}_{4} \mathrm{CNT}$ & $\begin{array}{l}\text { OTC: } 20 \mathrm{mg} / \mathrm{L} \\
\text { Catalyst: } 1.0 \mathrm{~g} / \mathrm{L}\end{array}$ & $93.6 \%$ in $80 \mathrm{~min}$ & $\begin{array}{l}\text { (Liu et al., } \\
\text { 2020) }\end{array}$ \\
\hline UV & $\begin{array}{l}\text { TTC: } 0.045 \mathrm{mM} \text {, } \\
\text { PMS: } 0.2 \mathrm{mM} \text {, } \\
\text { pH 3.1, } \\
\text { UV dose } 150 \mathrm{~mJ} / \mathrm{cm} 2\end{array}$ & $98 \%$ & $\begin{array}{l}\text { (Ao et al., } \\
\text { 2019) }\end{array}$ \\
\hline
\end{tabular}

Response surface methodology (RSM) is a set of statistical methods used to find the optimum

99 point based on independent variables. RSM is an experimental design that is widely used, and it

100 both minimizes the amount of waste that can be generated and provides an optimized result faster.

101 In light of this information, the effects of PS and PMS on oxytetracycline degradation, activated

102 by the use of both heat and initial $\mathrm{pH}$, were compared in this study. PS and PMS processes were

103 evaluated with a 4-factor 5-level central composite design, in which PS/PMS concentration, $\mathrm{pH}$,

104 temperature, and time were considered as independent variables. According to the optimized

105 results, the intermediate products were evaluated via UV-vis spectrum. This study is the first study

106 that compares the PS and PMS processes for OTC degradation. 


\section{$108 \quad 2.1 \quad$ Chemicals and Reagents}

109 The chemicals used in this study are in lab quality. Oxytetracycline $\left(\mathrm{C}_{22} \mathrm{H}_{24} \mathrm{~N}_{2} \mathrm{O}_{9}\right)$ was purchased 110 from Sigma Aldrich (Turkey). Sulfuric acid $\left(\mathrm{H}_{2} \mathrm{SO}_{4}\right.$, purity $\left.98 \%\right)$ and sodium hydroxide $(\mathrm{NaOH}$, 111 purity $\geq 97.0 \%$ ) were obtained from Merck, Turkey, and both were applied in $0.1 \mathrm{~N}$ and $0.1 \mathrm{~N}$ 112 concentration for $\mathrm{pH}$ adjustment.

\section{$113 \quad 2.2 \quad$ Experimental studies and reactor design}

114 The experiments were conducted in $50 \mathrm{~mL}$ Erlenmeyer flasks placed on a magnetic stirrer with a 115 heater (Weightech Instruments, WH-H320, Turkey). The flasks were closed and the temperature 116 of the samples was measured regularly by a temperature probe during experiments. The $\mathrm{pH}$ of each 117 sample was measured before and after the experiments by WTW Multi 9620 IDS, Turkey. The 118 initial concentration of OTC was $10 \mathrm{mg} / \mathrm{L}$ and measured at $355 \mathrm{~nm}$ wavelength by UV-visible 119 spectrophotometer (WTW-Photolab 6600 UV-vis, Turkey).

\subsection{Response Surface Methodology}

121 Response surface methodology was used to optimize the study both with PS and PMS experiments. 122 Four factor-five level design was applied by performing the independent variables, initial $\mathrm{pH}(\mathrm{A})$, 123 PS/PMS concentration (B), initial temperature (C), and time (D) on OTC degradation (y). The

124 levels were coded according to the $\alpha$ value of \pm 2 which can be calculated via Eq.7. Actual and 125 coded values of independent variables can be seen in Table 2.

$$
\alpha=\frac{x_{i}-x_{o}}{\Delta x}
$$

126 In Eq.7, $\alpha$ is code for independent variables, $x_{i}$ is the actual value of $x_{i}$ variable, $x_{0}$ is the actual 127 value in the med-point, and $\Delta \mathrm{x}$ shows the changes in $\mathrm{x}_{\mathrm{i}}$ variable. Experimental data were analyzed 128 with the quadratic equation as given in Eq. 8.

$$
y=a_{0}+\sum a_{i} x_{i}+\sum a_{i j} x_{i} x_{j}+\sum a_{i i} x_{i}^{2}
$$


129 In Eq.8, y shows the response value of design, $a_{o}$ shows the constant value of design, $a_{i}, a_{i i}$ and $a_{i j}$ 130 show the coefficients of the linear, quadratic, and interaction, $x_{i}$ and $x_{j}$ shows the independent 131 variables. In this study, the response is selected as OTC degradation efficiency. According to 132 selected levels and the number of independent variables, the number of runs in the central 133 composite design (CCD) were given in Table 3.

Table 2. Actual and coded values of independent variables

\begin{tabular}{lccccccc}
\hline \multirow{2}{*}{ Variables } & \multirow{2}{*}{ Units } & Code & \multicolumn{5}{c}{ Levels } \\
\cline { 4 - 8 } & & & -2 & -1 & 0 & +1 & +2 \\
\hline $\mathrm{pH}$ & & $\mathrm{A}$ & 3 & 5 & 7 & 9 & 11 \\
PS/PMS Concentration & $\mathrm{mM}$ & $\mathrm{B}$ & 1 & 2 & 3 & 4 & 5 \\
Temperature & ${ }^{\circ} \mathrm{C}$ & $\mathrm{C}$ & 30 & 45 & 60 & 75 & 90 \\
Time & $\min$ & $\mathrm{D}$ & 10 & 20 & 30 & 40 & 50 \\
\hline
\end{tabular}

135 The OTC degradation efficiencies were calculated according to Eq. (9)

$$
\% \text { OTC Degradation }=\frac{C_{0}-C_{t}}{C_{0}} \cdot 100
$$

136 where $C_{0}$ and $C_{t}$ are the initial and effluent OTC concentrations after a treatment time of t, 137 respectively. 
139 Table 3. CCD runs and OTC degradation efficiencies of PS and PMS Processes as the response

\begin{tabular}{|c|c|c|c|c|c|c|c|c|}
\hline \multirow{3}{*}{ Run } & \multirow{3}{*}{$\frac{\mathrm{pH}}{\mathrm{A}}$} & \multirow{3}{*}{$\begin{array}{c}\text { PS/PMS } \\
\text { Conc. }\end{array}$} & \multirow{3}{*}{$\begin{array}{c}\text { Temp. } \\
\text { C }\end{array}$} & \multirow{3}{*}{$\frac{\text { Time }}{\mathrm{D}}$} & \multicolumn{4}{|c|}{ OTC Degradation Efficiency } \\
\hline & & & & & \multicolumn{2}{|c|}{ PS Process } & \multicolumn{2}{|c|}{ PMS Process } \\
\hline & & & & & $\begin{array}{c}\mathrm{Y}_{1} \\
\text { Actual, \% }\end{array}$ & $\begin{array}{c}\mathrm{Y}_{1} \\
\text { Predicted, \% }\end{array}$ & $\begin{array}{c}\mathrm{Y}_{2} \\
\text { Actual, \% }\end{array}$ & $\begin{array}{c}\mathrm{Y}_{2} \\
\text { Predicted, \% }\end{array}$ \\
\hline 1 & $5(-1)$ & $2(-1)$ & $45(-1)$ & $20(-1)$ & 57.60 & 52.00 & 46.60 & 41.83 \\
\hline 2 & $9(+1)$ & $2(-1)$ & $45(-1)$ & $20(-1)$ & 65.50 & 64.50 & 56.80 & 55.12 \\
\hline 3 & $5(-1)$ & $4(+1)$ & $45(-1)$ & $20(-1)$ & 69.60 & 68.40 & 66.76 & 62.41 \\
\hline 4 & $9(+1)$ & $4(+1)$ & $45(-1)$ & $20(-1)$ & 80.60 & 78.30 & 73.90 & 72.71 \\
\hline 5 & $5(-1)$ & $2(-1)$ & $75(+1)$ & $20(-1)$ & 65.40 & 66.50 & 58.20 & 57.60 \\
\hline 6 & $9(+1)$ & $2(-1)$ & $75(+1)$ & $20(-1)$ & 79.30 & 80.10 & 70.50 & 70.63 \\
\hline 7 & $5(-1)$ & $4(+1)$ & $75(+1)$ & $20(-1)$ & 78.20 & 78.10 & 75.40 & 74.00 \\
\hline 8 & $9(+1)$ & $4(+1)$ & $75(+1)$ & $20(-1)$ & 87.50 & 89.20 & 81.80 & 84.04 \\
\hline 9 & $5(-1)$ & $2(-1)$ & $45(-1)$ & $40(+1)$ & 65.20 & 61.70 & 61.40 & 56.34 \\
\hline 10 & $9(+1)$ & $2(-1)$ & $45(-1)$ & $40(+1)$ & 74.30 & 71.50 & 68.90 & 66.07 \\
\hline 11 & $5(-1)$ & $4(+1)$ & $45(-1)$ & $40(+1)$ & 80.90 & 77.20 & 74.89 & 70.52 \\
\hline 12 & $9(+1)$ & $4(+1)$ & $45(-1)$ & $40(+1)$ & 87.20 & 84.30 & 79.50 & 77.27 \\
\hline 13 & $5(-1)$ & $2(-1)$ & $75(+1)$ & $40(+1)$ & 73.80 & 73.20 & 69.30 & 66.25 \\
\hline 14 & $9(+1)$ & $2(-1)$ & $75(+1)$ & $40(+1)$ & 84.70 & 84.20 & 74.20 & 75.72 \\
\hline 15 & $5(-1)$ & $4(+1)$ & $75(+1)$ & $40(+1)$ & 84.80 & 83.90 & 77.40 & 76.25 \\
\hline 16 & $9(+1)$ & $4(+1)$ & $75(+1)$ & $40(+1)$ & 89.60 & 92.30 & 82.20 & 82.74 \\
\hline 17 & $3(-2)$ & $3( \pm 0)$ & $60( \pm 0)$ & $30( \pm 0)$ & 56.20 & 61.20 & 43.20 & 52.04 \\
\hline 18 & $11(+2)$ & $3( \pm 0)$ & $60( \pm 0)$ & $30( \pm 0)$ & 82.30 & 82.00 & 73.60 & 71.82 \\
\hline 19 & $7( \pm 0)$ & $1(-2)$ & $60( \pm 0)$ & $30( \pm 0)$ & 60.50 & 64.10 & 55.40 & 60.03 \\
\hline 20 & $7( \pm 0)$ & $5(+2)$ & $60( \pm 0)$ & $30( \pm 0)$ & 87.60 & 88.60 & 85.20 & 87.62 \\
\hline 21 & $7( \pm 0)$ & $3( \pm 0)$ & $30(-2)$ & $30( \pm 0)$ & 53.70 & 62.80 & 48.01 & 57.72 \\
\hline 22 & $7( \pm 0)$ & $3( \pm 0)$ & $90(+2)$ & $30( \pm 0)$ & 89.70 & 85.20 & 81.60 & 78.96 \\
\hline 23 & $7( \pm 0)$ & $3( \pm 0)$ & $60( \pm 0)$ & $10(-2)$ & 72.00 & 72.90 & 59.40 & 61.68 \\
\hline 24 & $7( \pm 0)$ & $3( \pm 0)$ & $60( \pm 0)$ & $50(+2)$ & 82.10 & 85.80 & 70.10 & 74.88 \\
\hline 25 & $7( \pm 0)$ & $3( \pm 0)$ & $60( \pm 0)$ & $30( \pm 0)$ & 78.20 & 80.00 & 63.07 & 64.83 \\
\hline 26 & $7( \pm 0)$ & $3( \pm 0)$ & $60( \pm 0)$ & $30( \pm 0)$ & 80.80 & 80.00 & 65.80 & 64.83 \\
\hline 27 & $7( \pm 0)$ & $3( \pm 0)$ & $60( \pm 0)$ & $30( \pm 0)$ & 81.0 & 80.0 & 65.63 & 64.83 \\
\hline
\end{tabular}




\section{Results and Discussion}

141 Before determining the levels given in the matrix in Table 2, pre-studies were done, according to

142 the studies conducted in the literature (Table 1), which are mostly for PS activation. Thermal and

143 alkali activation of PS and PMS were studied for the points given in Table 4, and it was observed

144 that the effect of $\mathrm{pH}$ and temperature were significant. Therefore, the level of $\mathrm{pH}$ was selected,

145 starting from $\mathrm{pH} 3$ to $\mathrm{pH} 11$ and the levels for temperature was ranged from $30-90^{\circ} \mathrm{C}$. Since high

146 degradation efficiencies were achieved under high PMS concentration and high required time,

147 lower values of both parameters were chosen as levels (Table 2).

Table 4. Pre-studies for determining the levels of CCD

\begin{tabular}{ccccccc}
\hline Runs & $\mathrm{pH}$ & $\begin{array}{c}\text { PS Conc., } \\
\mathrm{mM}\end{array}$ & $\begin{array}{c}\text { PMS Conc., } \\
\mathrm{mM}\end{array}$ & $\begin{array}{c}\text { Time, } \\
\min \end{array}$ & $\begin{array}{c}\text { Temperature, } \\
{ }^{\circ} \mathrm{C}\end{array}$ & $\begin{array}{c}\text { Degradation } \\
\text { Eff., } \%\end{array}$ \\
\hline 1 & 7.0 & 5 & - & 60 & 70 & 89.5 \\
2 & 7.0 & 5 & - & 60 & 90 & 95.0 \\
3 & 2.5 & 5 & - & 60 & 70 & 80.6 \\
4 & 2.5 & 5 & - & 60 & 30 & 75.6 \\
5 & 7.0 & - & 5 & 60 & 70 & 62.1 \\
6 & 11.0 & - & 5 & 60 & 70 & 99.3 \\
7 & 2.5 & - & 5 & 60 & 70 & 88.1 \\
8 & 2.5 & - & 5 & 60 & 30 & 88.1 \\
\hline
\end{tabular}

149 According to the central composite design, the runs were designed in a batch mode as given in

150 Table 3. The response of CCD was selected as OTC degradation. The PS and PMS processes were 151 evaluated separately, and compared based on degradation, active species, and intermediate 152 products.

\section{$153 \quad 3.1 \quad$ Model Accuracy}

154 All runs given in Table 3 were studied with the PS process by considering the concentrations of B 155 parameter as PS concentrations (Table 2). Regarding the obtained responses (Table 3), the 156 quadratic model was used as the most suitable model to explain the relationship between the 157 experienced and the values of OTC degradation estimated using ANOVA results in the PS process. 158 The results of the statistical analysis of ANOVA are shown in detail in Table 5. The results 159 obtained in the studies with PS show that the oxidation performance gives satisfactory results. By 160 considering the regression coefficients, the reliability between the actual data and the predicted 
161 values of the responses was proved by the quadratic model. Variance analysis values were given

162 in Table 5 to better understand the optimization performance of the study. The regression

163 coefficient $\left(\mathrm{R}^{2}\right)$ was determined as above $90 \%$, which shows the model performance is good. The

164 fit of the model appears to be in good accordance with the $\mathrm{R}^{2}$ with adjusted $\mathrm{R}^{2}$ values. Besides,

165 there is a slight difference between the experimental and predicted values shown in Table 3,

166 resulting in a low coefficient of variation value (C.V. value). The accuracy and repeatability of the

167 experiments were confirmed by this low C.V. value (C.V. <10\%) (Can-Guven et al., 2020; Varank,

168 2020). The adequate precision value is required to be greater than 4 to measure the predicted

169 response and the corresponding error value (the signal-to-noise ratio)(Rahdar et al., 2020). In this

170 study, it was found to be over 4 (Table 5). The fitness of the model can be considered as desired.

171 The non-significant lack of fit values can be submitted as the best fit (Varank, 2020).

172 Table 5. ANOVA results of the quadratic model for Heat-activated PS oxidation

\begin{tabular}{|c|c|c|c|c|c|c|}
\hline Source & $\begin{array}{l}\text { Sum of } \\
\text { Squares }\end{array}$ & df & $\begin{array}{l}\text { Mean } \\
\text { Square } \\
\end{array}$ & $\begin{array}{l}\text { F- } \\
\text { value }\end{array}$ & P-value & Significance \\
\hline Model & 2721.95 & 14 & 194.42 & 9.11 & 0.0002 & \\
\hline A-pH & 653.93 & 1 & 653.93 & 30.65 & 0.0001 & HS \\
\hline B-PS/PMS & 898.40 & 1 & 898.40 & 42.11 & $\begin{array}{r}< \\
0.0001\end{array}$ & HS \\
\hline C-Temperature & 751.44 & 1 & 751.44 & 35.22 & $\begin{array}{r}< \\
0.0001\end{array}$ & HS \\
\hline D-Time & 246.44 & 1 & 246.44 & 11.55 & 0.0053 & $\mathrm{~S}$ \\
\hline $\mathbf{A B}$ & 6.72 & 1 & 6.72 & 0.32 & 0.5850 & NS \\
\hline $\mathbf{A C}$ & 1.31 & 1 & 1.31 & 0.06 & 0.8085 & NS \\
\hline AD & 7.61 & 1 & 7.61 & 0.36 & 0.5615 & NS \\
\hline BC & 22.09 & 1 & 22.09 & 1.04 & 0.3290 & NS \\
\hline BD & 0.88 & 1 & 0.88 & 0.04 & 0.8426 & NS \\
\hline CD & 8.70 & 1 & 8.70 & 0.41 & 0.5350 & NS \\
\hline $\mathbf{A}^{2}$ & 94.38 & 1 & 94.38 & 4.42 & 0.0572 & NS \\
\hline $\mathbf{B}^{2}$ & 17.67 & 1 & 17.67 & 0.83 & 0.3808 & NS \\
\hline $\mathbf{C}^{2}$ & 47.85 & 1 & 47.85 & 2.24 & 0.1601 & NS \\
\hline $\mathbf{D}^{2}$ & 0.52 & 1 & 0.52 & 0.03 & 0.8782 & NS \\
\hline Residual & 256.02 & 12 & 21.34 & & & \\
\hline Lack of Fit & 251.16 & 10 & 25.12 & 10.33 & 0.0914 & NS \\
\hline Pure Error & 4.86 & 2 & 2.43 & & & \\
\hline Cor Total & 2977.97 & 26 & & & & \\
\hline $\boldsymbol{R}^{2}$ & 0.914 & & & & & \\
\hline Adjusted $R^{2}$ & 0.814 & & & & & \\
\hline C.V. \% & 6.09 & & & & & \\
\hline Adeq. Precision & 11.69 & & & & & \\
\hline
\end{tabular}


174 Besides, the $\mathrm{P}$ values of each parameter given in Table 5 were evaluated according to the $95 \%$ 175 confidence interval. Parameters with a value of $\mathrm{P}$ less than 0.05 were considered as significant and 176 those with a value lower than 0.0001 were considered as highly significant. It can be seen from 177 Table 5 that the linear terms of the selected independent variables were significant, but quadratic 178 forms were not so effective. The equation obtained based on these data is obtained as given in 179 Eq.10.

$$
\begin{aligned}
y_{1}=80.02+ & 5.225 A+6.117 B+5.60 C+3.208 D-0.65 A B+0.288 A C \\
& -0.688 A D-1.175 B C-0.225 B D-0.738 C D-2.104 A^{2} \\
& -0.904 B^{2}-1.492 C^{2}-0.154 D^{2}
\end{aligned}
$$

180 The coefficients in Eq.10 assistance to understand the importance of the effect of variables on the 181 response, in terms of both magnitude and signs. Therefore, the fact that all independent variables 182 (A, B, C, and D) have positive coefficients indicates that these variables have a positive effect on 183 OTC degradation. Rather, all the coefficients belong to the interaction, and the quadratic terms of 184 the independent variables (except AC) have negative signs indicating that they have negative 185 effects on OTC degradation. Moreover, the highest coefficient within all independent variables 186 belongs to PS concentration. According to this information, time can be considered as the less 187 effective parameter. Since the P-values of independent variables are significant, we can also 188 express that all independent variables have a high impact on OTC degradation.

189 The same model used for the PS process was also modeled for the PMS process by applying the 190 concentrations determined in the B parameter as PMS. The CCD is designed as quadratic and the 191 predicted values of the model outputs were given in Table 2. The results obtained in the studies 192 with PMS show that it gives acceptable results when the degradation performance is examined. 193 The regression coefficient of the model was obtained as 0.89 and C.V was less than $10 \%$. Besides, 194 as mentioned above, the adequate precision value was used to measure the signal-to-noise ratio. A 195 higher value than 4 shows the accuracy of the model. P-values of the parameters can also be seen 196 in Table 6. The model was evaluated with a confidence interval of $95 \%$, and it can be seen that the 197 linear forms of the independent variables were the most effective within all components of the 198 quadratic model. The equation obtained according to the ANOVA results was given in Eq.11. 


$$
\begin{aligned}
y_{2}=64.833+ & 4.944 A+6.898 B+5.31 C+3.301 D-0.745 A B-0.066 A C \\
& -0.89 A D-1.047 B C-1.60 B D-1.464 C D-0.726 A^{2} \\
& +2.249 B^{2}+0.876 C^{2}-0.862 D^{2}
\end{aligned}
$$

\begin{tabular}{|c|c|c|c|c|c|c|}
\hline Source & $\begin{array}{l}\text { Sum of } \\
\text { Squares }\end{array}$ & dff & $\begin{array}{l}\text { Mean } \\
\text { Square } \\
\end{array}$ & $\begin{array}{l}\text { F- } \\
\text { value }\end{array}$ & P-value & Significance \\
\hline Model & 2951.37 & 14 & 210.81 & 6.90 & 0.0009 & \\
\hline A-pH & 586.58 & 1 & 586.58 & 19.19 & 0.0009 & HS \\
\hline B-PS/PMS, mM & 1141.95 & 1 & 1141.95 & 37.36 & $\begin{array}{r}< \\
0.0001\end{array}$ & HS \\
\hline $\begin{array}{l}\text { C-Temperature, } \\
{ }^{\circ} \mathrm{C}\end{array}$ & 676.62 & 1 & 676.62 & 22.14 & 0.0005 & $\mathrm{HS}$ \\
\hline D-Time, min & 261.54 & 1 & 261.54 & 8.56 & 0.0127 & $S$ \\
\hline $\mathbf{A B}$ & 8.93 & 1 & 8.93 & 0.2920 & 0.5988 & NS \\
\hline $\mathbf{A C}$ & 0.07 & 1 & 0.07 & 0.0023 & 0.9629 & NS \\
\hline AD & 12.64 & 1 & 12.64 & 0.4136 & 0.5322 & NS \\
\hline BC & 17.53 & 1 & 17.53 & 0.5734 & 0.4635 & NS \\
\hline BD & 40.87 & 1 & 40.87 & 1.34 & 0.2700 & NS \\
\hline CD & 34.30 & 1 & 34.30 & 1.12 & 0.3103 & NS \\
\hline $\mathbf{A}^{2}$ & 11.22 & 1 & 11.22 & 0.3670 & 0.5559 & NS \\
\hline $\mathbf{B}^{2}$ & 107.95 & 1 & 107.95 & 3.53 & 0.0847 & NS \\
\hline $\mathbf{C}^{2}$ & 16.38 & 1 & 16.38 & 0.5359 & 0.4782 & NS \\
\hline $\mathbf{D}^{2}$ & 15.86 & 1 & 15.86 & 0.5190 & 0.4851 & NS \\
\hline Residual & 366.80 & 12 & 30.57 & & & \\
\hline Lack of Fit & 362.12 & 10 & 36.21 & 15.49 & 0.0621 & NS \\
\hline Pure Error & 4.68 & 2 & 2.34 & & & \\
\hline Cor Total & 3318.17 & 26 & & & & \\
\hline$R^{2}$ & 0.8895 & & & & & \\
\hline Adjusted $R^{2}$ & 0.7605 & & & & & \\
\hline C.V. \% & 8.16 & & & & & \\
\hline Adeq. Precision & 11.11 & & & & & \\
\hline
\end{tabular}

199

Table 6. ANOVA results of the quadratic model for Heat-activated PMS oxidation

HS: Highly significant, S: significant, NS: Non-significant

201 The Pareto chart also illustrates the influence of independent variables on OTC degradation using 202 Eq. 12, where $\beta$ i represents the coefficient of the independent variables (Majumdar and Pal, 2020).

$$
P_{i}=\left(\frac{\beta_{i}^{2}}{\sum \beta_{i}^{2}}\right) \cdot 100(i \neq 0)
$$

203 Pareto chart was prepared for PS and PSM processes and showed in Figure 1a and Figure 1b, 204 respectively. The independent parameters which are effective more than $1 \%$ are considered for 
205 Pareto charts. For both processes, the most effective parameter can be revealed as PS/PMS 206 concentration (B) and followed by temperature (C), $\mathrm{pH}(\mathrm{A})$, and time (D). The $\mathrm{P}$ values of the 207 interaction and quadratic terms of the models were higher than 0.05 which shoes the low/non208 impact on the OTC degradation. The percentage of the effects of these terms is less than $4 \%$.

a.

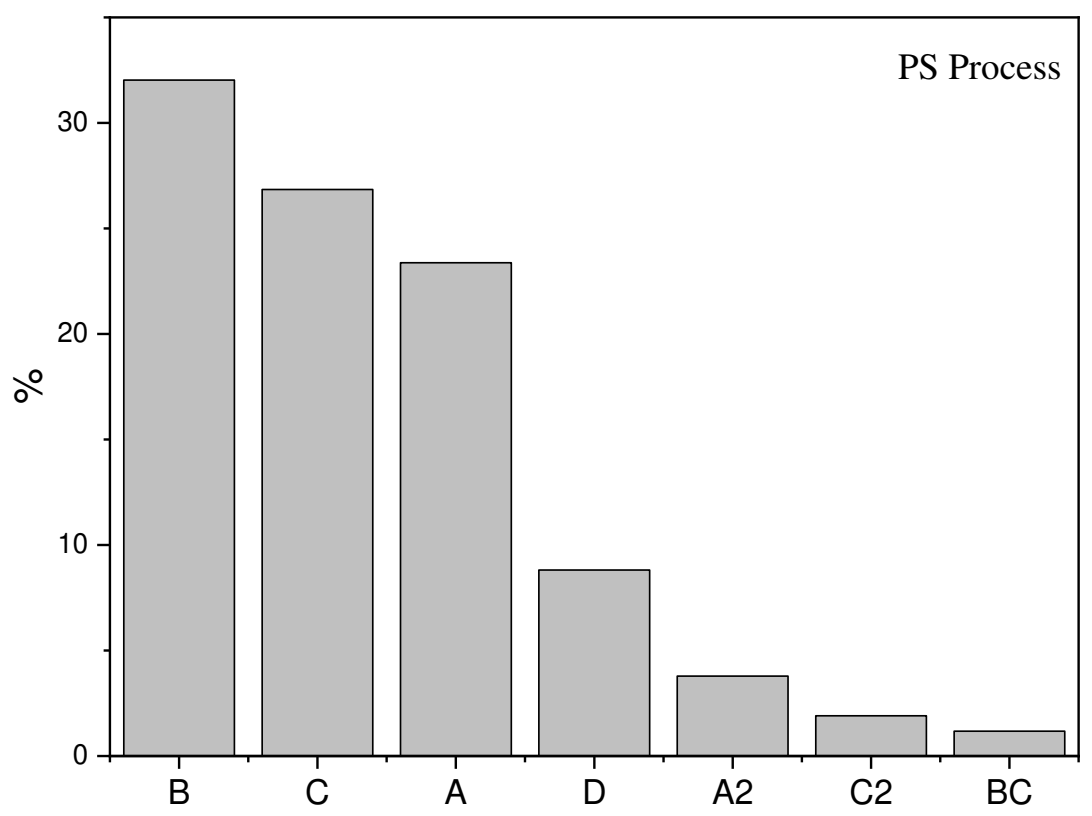

b.

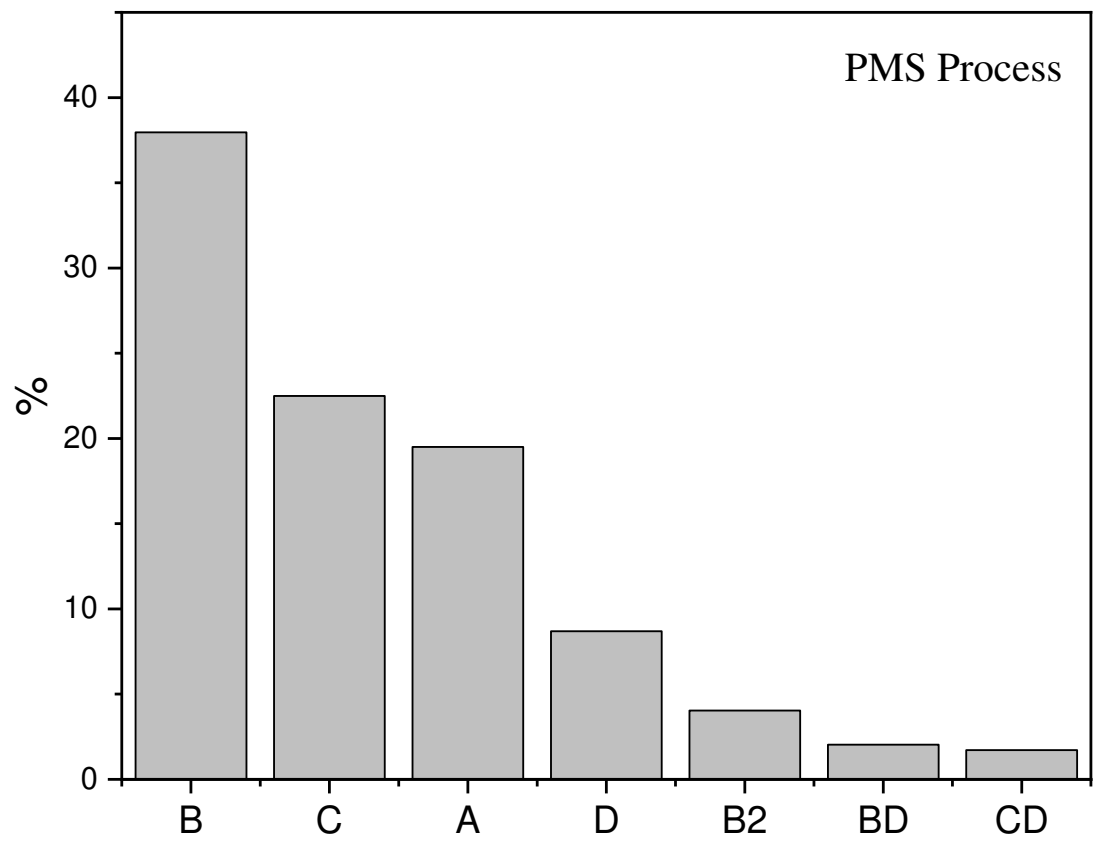

Figure 1. Pareto charts for (a) PS process and (b) PMS process 
210 We can also analyze the adequacy of the model by the normal probability graphs which define the 211 difference between the predicted results and the experimental results. Normal probability plots 212 used to evaluate the normality of residues are obtained by plotting predicted residues versus 213 observed residues as given in Figure 2. It implies that the quadratic regression model that appears 214 to be distributed along a straight line is satisfactory.

a.

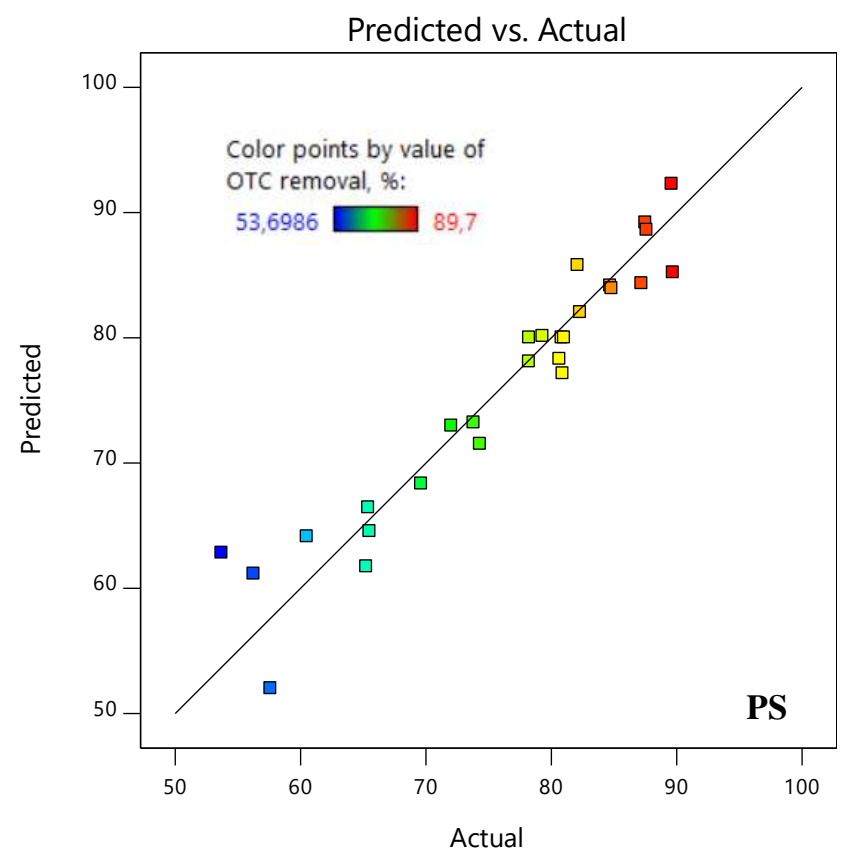

b.

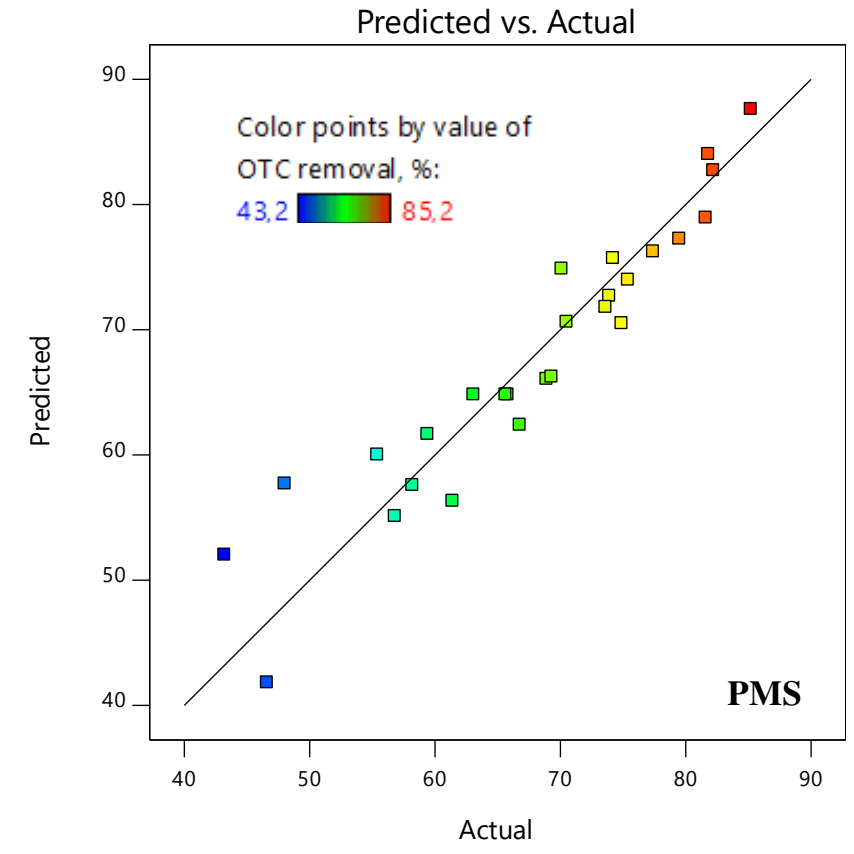

Figure 2. Actual vs. predicted values for (a) PS and (b) PMS oxidation 


\subsection{Comparison of PS and PMS Processes}

217 Three-dimensional (3D) response surface graphs show the effect of only two factors on OTC 218 degradation efficiency, while the other two factors are fixed at the midpoint $(\alpha=0)$. Factors can 219 be evaluated within the ranges given in Table 1 . The effect of independent variables can be 220 observed via the 3D plot generated via CCD. These plots were prepared for PS and PMS processes 221 separately and the comparison of the processes was established accordingly. As can be seen from 222 the surface graphs given in Figure 3, the OTC degradation efficiencies were increasing with the 223 increment on all independent variables. This was also gathered from ANOVA results. The higher 224 degradation efficiencies were expected with the increase of PS concentrations since it is the most 225 important variable of the process (Figure 3.a)(Can-Guven et al., 2020). According to Figure 3.a, 226 when the PS concentration was higher than $3 \mathrm{mM}$, and $\mathrm{pH}$ is higher than $\mathrm{pH} 7$, the degradation 227 efficiencies can be obtained at a higher value than 80\%. As per Figure 3.b and Figure 3.c, with 228 higher values than $60^{\circ} \mathrm{C}$ for temperature, $30 \mathrm{~min}$, and $\mathrm{pH} 7$, the degradation efficiencies are higher 229 than $80 \%$. This can also be understood from the intercept of Eq.9, which is 80. All 3D figures were 230 illustrated for OTC degradation efficiencies versus 2 independent variables, while the other two 231 parameters were selected at the center point. The highest degradation efficiency can be seen in 232 Figure 3.e as approximately $92 \%$ with the highest PS concentration (5 mM), highest time (50 min) 233 at $\mathrm{pH} 7$ and $60^{\circ} \mathrm{C}$.

234 Figure 3.b, Figure 3.d, and Figure 3.f show the effect of temperature with other independent 235 variables on OTC degradation. Considering that the increase in temperature has a positive effect 236 on both increasing the efficiency of sulfate radicals and degradation of OTC, a value at high 237 temperature will be optimum as expected. Likewise, the effect of the $\mathrm{pH}$ factor is an effective 238 parameter on PS processes. PS can be activated at low $\mathrm{pH}$ values but also at alkaline conditions. 239 Therefore, the effect of $\mathrm{pH}$ was screened in a very broad spectrum $(\mathrm{pH} 3-\mathrm{pH} 11)$. According to 240 Figure 3.a, 3.b, and 3.c, OTC degradation obtained at alkaline conditions. 


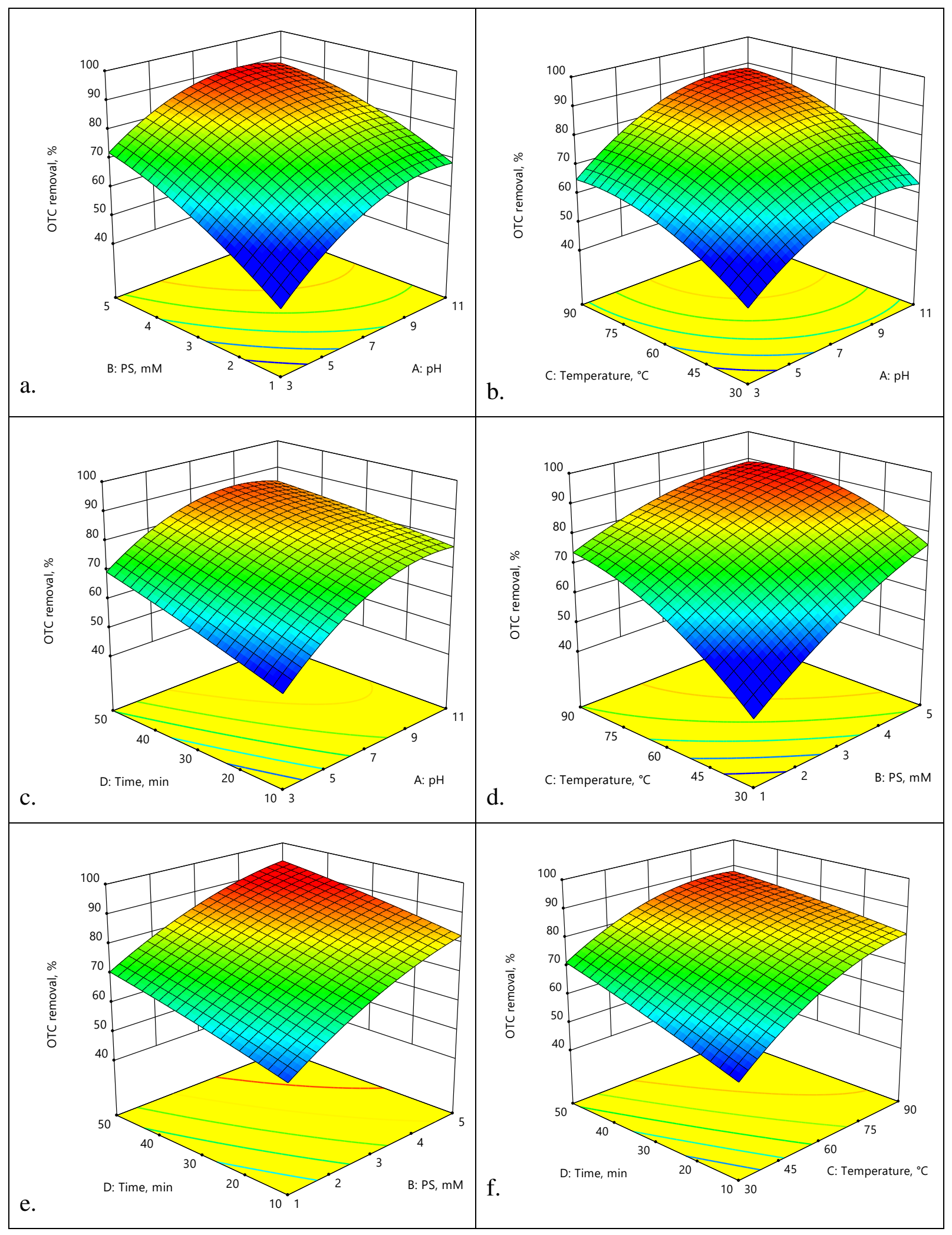

Figure 3. 3D plots for heat activated-PS oxidation 


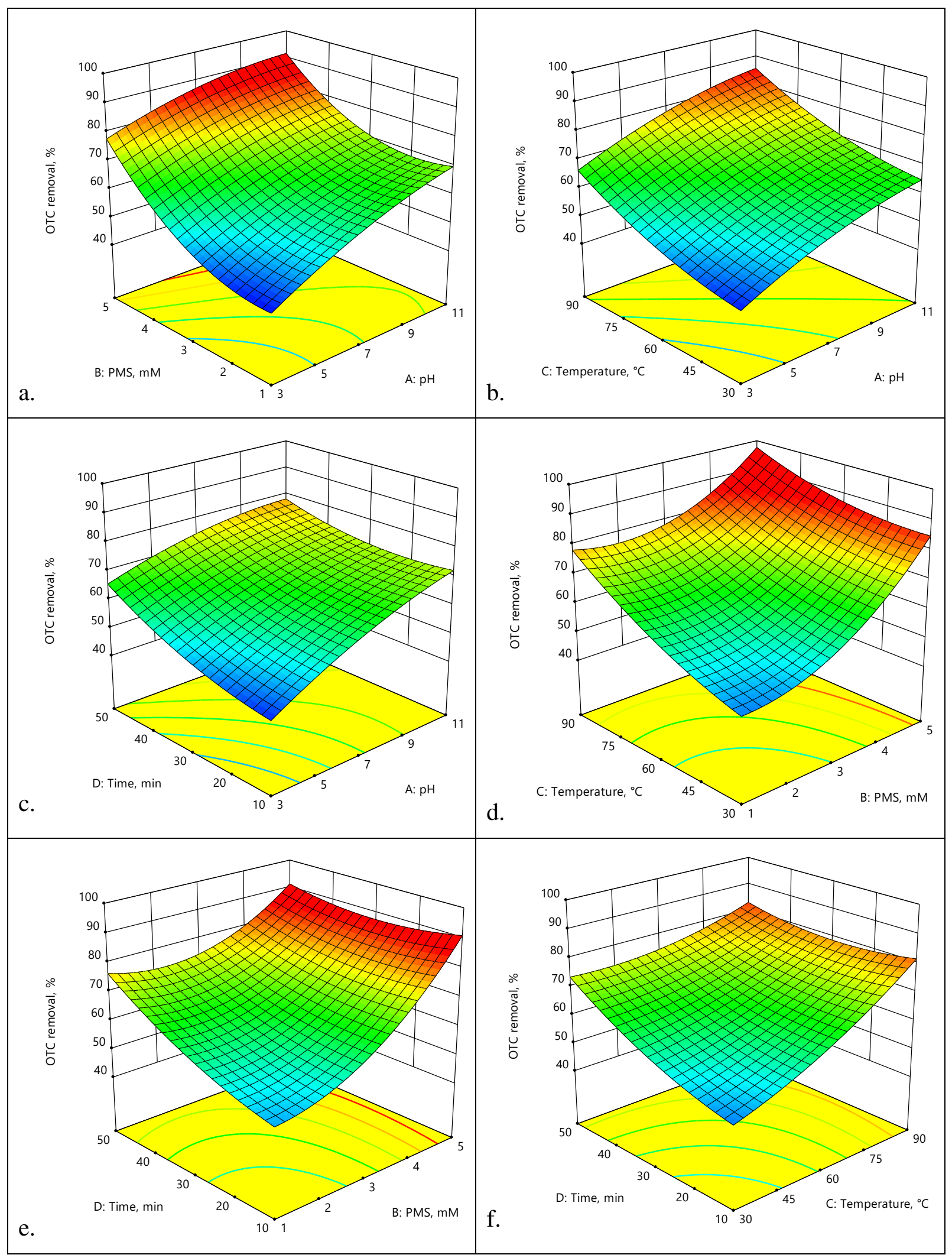

Figure 4. 3D plots for heat activated-PS oxidation 
245 The linear effects of independent variables in Equation 10 are positive, which shows that all 246 parameters are positively affecting. This can also be seen from Figure 4 that OTC degradation is 247 linear to the increment in the values of each parameter. The highest coefficient within all 248 independent variables belongs to PMS concentration, which shows that it is the most effective 249 parameter within all. Similarly, it can be gathered from Figure 4 that the PMS concentration is the 250 most effective parameter, while the effect of time is lower than the others. This effect of time, 251 which is less than other parameters, can be seen from Figure 4.c, 4.e, and 4.f and also from P-

252 Value from Table 5. The graph with the highest removal efficiency (approximately 98\%) was 253 attained in Figure 4.d, and it was obtained in the case where the PMS concentration was the highest. 254 Also, from Figure 4.d, higher OTC degradation with the increment of temperature can be caused 255 by the formation of hydroxyl radicals at higher temperatures. To have a higher degradation than $25680 \%$, all parameters should be in a higher alpha value than 0.9 , which means that the conditions 257 higher than $\mathrm{pH} 9,4 \mathrm{mM}$ PMS concentration, $75^{\circ} \mathrm{C}$, and $40 \mathrm{~min}$ of reaction time. However, this 258 situation is different for the case where the PMS concentration is $5 \mathrm{mM}$ at the highest point, the 259 effectiveness of all other parameters is low (Figure 4.a, 4.d, and 4.e). Especially, the time parameter 260 is not affecting, when PMS concentration is $5 \mathrm{mM}$; the OTC degradation efficiency is 261 approximately $90 \%$ regardless of time (Figure 4.e). This shows that the effectiveness of PMS can 262 be seen at the highest concentration.

\subsection{Optimization of PS and PMS Processes}

264 Eq. 10 and Eq. 11 were optimized to understand the conditions under which the highest removal 265 efficiency is at the levels of the experimental matrix given in Table 2. Both processes were 266 optimized taken into account all parameters, and it was obtained that the degradation efficiencies 267 that could be obtained for PS and PMS processes were 89.7\% and 84.0\%, respectively (Table 7). 268 Accordingly, the optimum $\mathrm{pH}$ is approximately 9, and the optimum temperature was obtained as 26972.9 and $75.0^{\circ} \mathrm{C}$ for PS and PMS processes, respectively. It has been gathered that while 26.5 min 270 of reaction time is needed for the PS process, $20 \mathrm{~min}$ is sufficient for PMS. Figure 2.e shows that 271 the degradation efficiency is the same regardless of the time when the PS/PMS is $4 \mathrm{mM}$. 272 Nevertheless, a low reaction time is required, the efficiency of the PMS process was lower than 273 the PS process. Ji et al. (2016) emphasized in their study that 240 min was needed to achieve $100 \%$ 274 removal in the persulfate process they activated with heat (Table 1). Malakotian et al. (2019) 
275 reported that for OTC removal, 90 min were needed for approximately $93 \%$ removal with $4 \mathrm{mM}$ 276 PS they activated with magnetite and UV. In their sonocatalysis with peroxydisulfate study by 277 Kumar Subramani et al. (2019), it was found that $1 \mathrm{~h}$ was required for degradation of OTC at a 278 concentration of $2 \mathrm{mg} / \mathrm{L}$ with $99 \%$ yield (In this study, the temperature used is $55^{\circ} \mathrm{C}$ and the PS 279 concentration was $1 \mathrm{~g} / \mathrm{L}$ ). According to the literature and results of this study, it can be revealed 280 that the use of PS is more effective than the PMS process.

281 Reaction $\mathrm{pH}$ is important in PS/PMS processes for two reasons, one is for conversion to sulfate 282 radical and the other is that there are four different types of OTC at different $\mathrm{pH}$. This may cause 283 generated active species against different OTC types to give different reactions. Liu et al. (2016b) 284 mentioned that the sulfate radical anion may have a negative effect on anionic and zwitterionic 285 organic compounds. OTC molecule exists in the cationic form at acidic pHs, while it exists in 286 zwitterionic form when $\mathrm{pH}$ is between $\mathrm{pH} 3$ and $\mathrm{pH}$. The reason for the low effects of both PS 287 and PMS processes between $\mathrm{pH}$ 3-7 can also be explained in this way. To understand this issue, $\mathrm{k}_{\mathrm{t}}$ 288 values were calculated at the optimum point based on the data given in Table 7. PS and PMS 289 concentration was selected as $4 \mathrm{mM}$ to obtain the same value, and the temperature was selected as $29075^{\circ} \mathrm{C}$. The calculation of $\mathrm{k}_{\mathrm{t}}$ values was calculated based on Equation 13.

$$
C=C_{0} \cdot \exp \left(-k_{t} \cdot t\right)
$$

291 Where $\mathrm{C}_{0}$ and $\mathrm{C}$ were the initial and effluent concentration $(\mathrm{mg} / \mathrm{L})$ at " $\mathrm{t}$ " time $(\mathrm{min})$ and $\mathrm{k}_{\mathrm{t}}$ is the 292 pseudo-first-order constant $\left(\mathrm{min}^{-1}\right)$. Exponential function versus time was prepared at different $\mathrm{pH}$ 293 values to calculate $\mathrm{k}_{\mathrm{t}}$, and the results can be seen in Figure 5. Accordingly, the optimum pH can 294 also be obtained from $\mathrm{k}_{\mathrm{t}}$ as $\mathrm{pH}$ 9. After $\mathrm{pH}$ 9, while the $\mathrm{k}_{\mathrm{t}}$ values for PS were reduced, it stayed the same for the PMS process. The form of $\mathrm{OTC}^{2-}$ which exits on $\mathrm{pH} 11$ does not react well with PS activation (Liu et al., 2016b). Suggested that the active species on the PS process is known that mostly $\mathrm{SO}_{4} \cdot$ radicals existed under alkaline conditions; the reaction of $\mathrm{SO}_{4} \cdot$ radicals and $\mathrm{OH}^{-}$can decrease the effectiveness of $\mathrm{SO}_{4}$. radicals which causes low OTC degradation efficiencies (Eq.6). When $\mathrm{k}_{\mathrm{t}}$ values at acidic and alkali conditions were compared, the PS process seems to be more effective. Since it is known that only $\mathrm{SO}_{4} \cdot$ radicals exit at the PS process, it can be concluded that both $\mathrm{SO}_{4} \cdot$ radicals are more effective than $\mathrm{OH} \cdot$ radicals in both PS and PMS processes. 
Table 7. Optimum conditions for Heat activated-PS/PMS oxidation

\begin{tabular}{lcc}
\hline \multicolumn{1}{c}{ Conditions } & PS & PMS \\
\hline A-pH & 8.9 & 9.0 \\
B-PS/PMS, $\mathbf{m M}$ & 3.9 & 4.0 \\
C-Temperature, ${ }^{\circ} \mathbf{C}$ & 72.9 & 75.0 \\
D-Time, min & 26.5 & 20.0 \\
Max. Removal efficiency, $\%$ & 89.7 & 84.0 \\
\hline
\end{tabular}

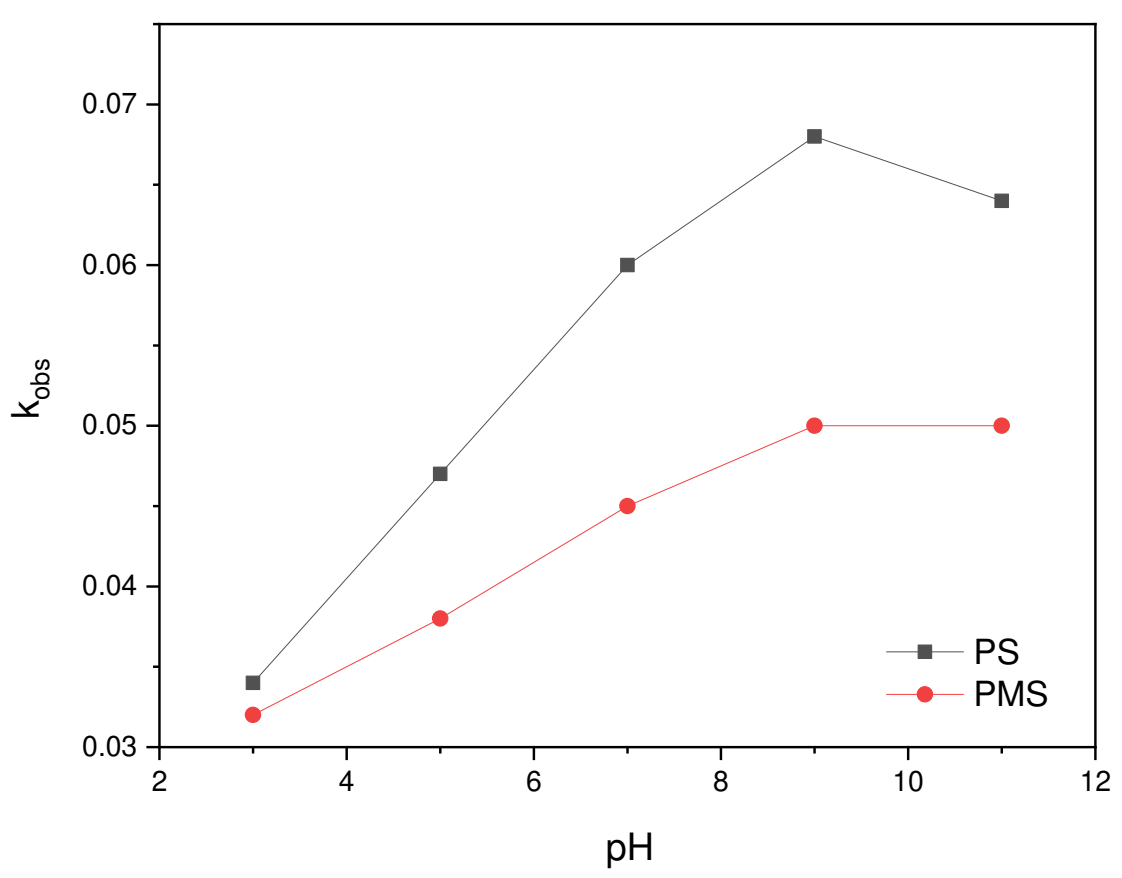

Figure 5. $\mathrm{k}_{\mathrm{t}}$ values at different $\mathrm{pH}$ values with Ps and PMS processes

306 The accuracy of the model expresses with the confidence interval (Ulucan-Altuntas and Debik, 307 2020) which is calculated via Equation 14.

$$
C I=\bar{x} \pm z \frac{S}{\sqrt{n}}
$$

308 Where $\mathrm{CI}$ is the confidence interval, $\bar{x}$ is the sample mean, $\mathrm{z}$ is the value of confidence level value, $309 \mathrm{~s}$ is the sample standard deviation and $\mathrm{n}$ is the number of samples. The confidence level was 310 selected as $95 \%$ for this study, thus, $\mathrm{z}$ was used as 1.96. CI was determined as \pm 4.2 and \pm 4.6 for 311 PS and PMS processes. The studies were established three times at the optimum point given in 
312 Table 7 for both processes and the results were 87.6 \pm 4.2 and 80.2 \pm 4.6 for PS and PMS processes, 313 respectively, which are acceptable for the prepared model.

a.

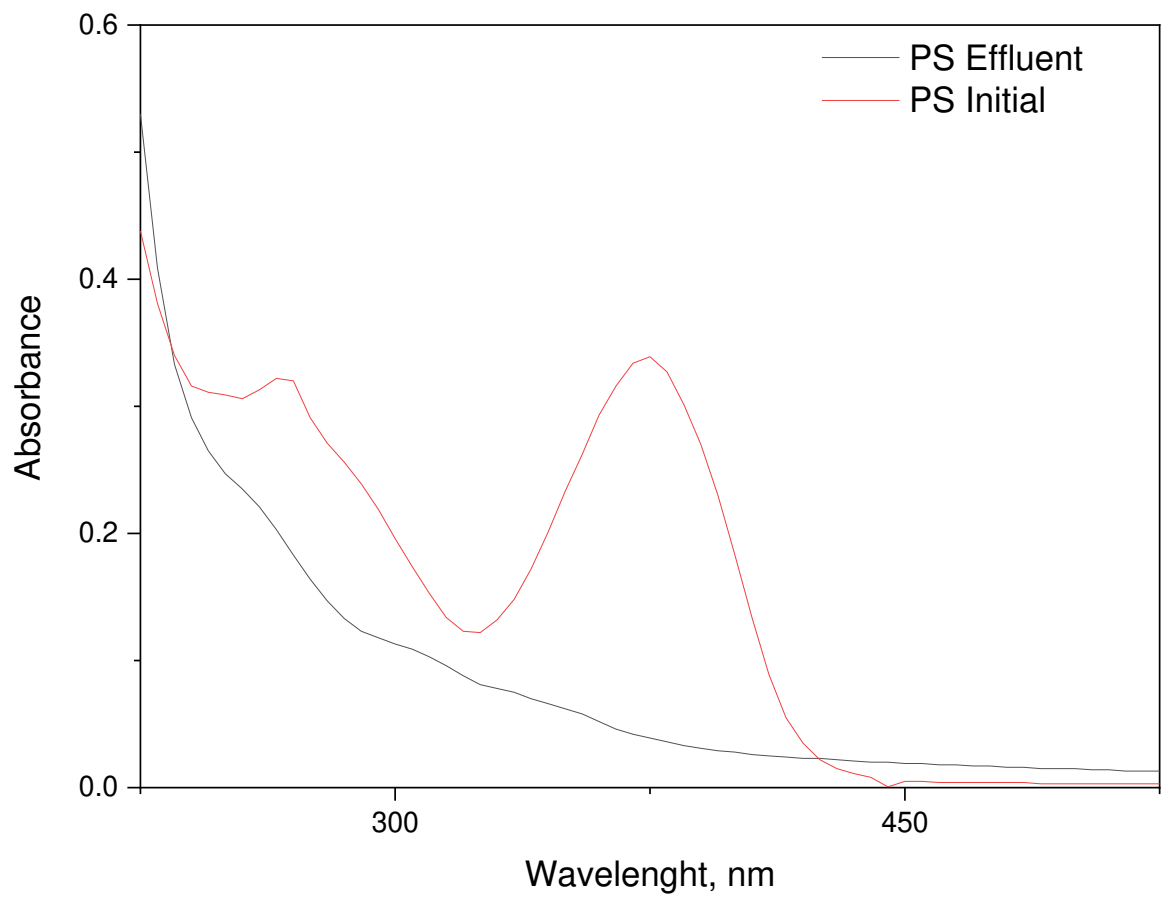

b.

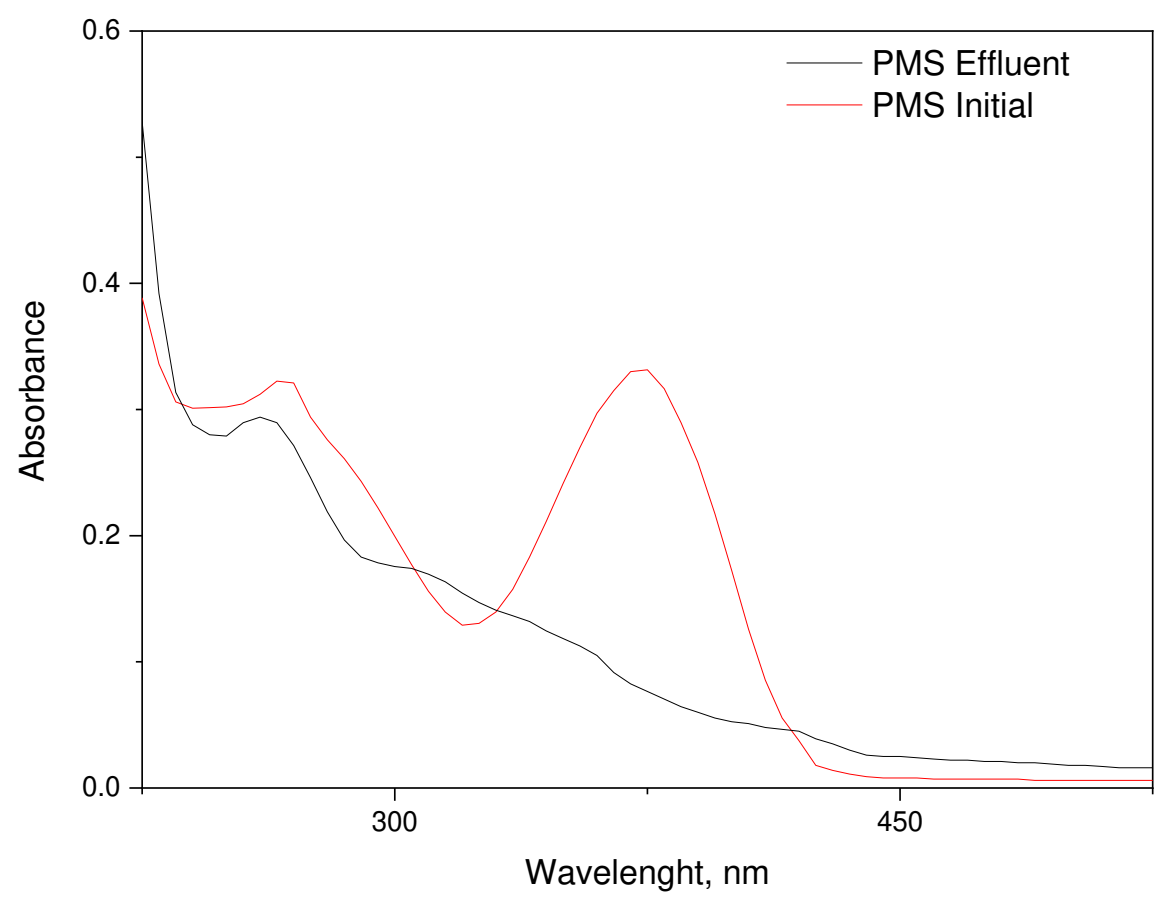

314 Figure 6. UV-vis spectrum of OTC samples before and after treatment by (a) PS and (b) PMS 
316 To analyze the degradation intermediate products, UV-Visible wavelength spectrum was used for

317 the samples studied at the optimum point given in Table 7. The spectrums of the samples before 318 and after treatment by PS and PMS processes were given in Figure 6.a and Figure 6.b, respectively.

319 Two wide peaks were observed at the initial OTC samples. While the wide peak between $320 \mathrm{~nm}$ 320 and $400 \mathrm{~nm}$ disappeared in the effluent samples of both processes, the peak at $265 \mathrm{~nm}$ seen in the 321 initial sample was shifted to $255 \mathrm{~nm}$ in the effluent sample of the PMS process (Fig.6.b) but was 322 not observed in the PS process (Fig.6.a). Since OTC is a naphthol ring, naphthalene is an expected 323 by-product as a result of degradation. The presence of naphthalene has been stated in the literature 324 that the OTC compound will be formed by breaking the stable naphthol ring (Kumar Subramani 325 et al., 2019). The wide peak seen at $255 \mathrm{~nm}$ can be seen as the transformation of naphthene as a 326 result of degradation. Looking at the absorbance values around $220 \mathrm{~nm}$, an increase in height is seen as a result of both processes. This case shows simple acidic compounds with $-\mathrm{C}=\mathrm{O}$ - bonds, 328 such as acetic acid. This can be stated as the last step (by-product) of degradation. The issue of 329 determining the degradation by-products and complete mineralization will be investigated in 330 further studies.

\section{Conclusion}

332 This study was conducted to compare PS and PMS processes on OTC degradation by optimization 333 with central composite design. The independent variables were selected as initial pH, PS/PMS 334 concentration, temperature, and time for both processes in which PS/PMS concentration was 335 determined as the most important variables within them. For both processes, the importance of the 336 independent variables was determined as PS/PMS concentration $>$ temperature $>$ initial $\mathrm{pH}>$ time. 337 According to CCD models, only the linear terms were concluded as the effective independent 338 variables for both processes. Kinetic constants for pseudo-first-order for different $\mathrm{pH}$ values 339 calculated at highest PS/PMS concentrations showed that PMS has slightly higher k constants, 340 meaning better in OTC degradation. Kinetic constants were attained as 0.068 and $0.071 \mathrm{~min}^{-1}$ for 341 PS and PMS processes, respectively. According to optimum conditions, optimum $\mathrm{pH}$ is $\mathrm{pH}$ 9, 342 PS/PMS concentration is approximately $4 \mathrm{mM}$, the temperature is $72.9^{\circ} \mathrm{C}$ and $75^{\circ} \mathrm{C}$ and the 343 required time was $26.5 \mathrm{~min}$ and $20 \mathrm{~min}$ for PS and PMS processes, respectively. Besides, according 344 to the UV-vis spectrum, while the peak for OTC decreased for both processes, peak height at 225 $345 \mathrm{~nm}$ showed that compounds with $-\mathrm{C}=\mathrm{O}$ - bonds were increased at both $\mathrm{PS}$ and PMS processes All 
346 results promote PS is more effective than the PMS process. In light of this information, additional

347 processes can be used in PS/PMS activation to lower the required PS/PMS concentration.

\section{Ethics declarations}

349 - Completing Interest: The Authors declare that there is no conflict of interest.

350 - Ethical Approval: Not applicable (This study did not recruit any human/animal subjects.)

351 - Consent to Participate: Not applicable (This study did not recruit any human subjects.)

352 - Consent to Publish: Not applicable (This study is not published previously)

353 Funding - Not applicable

\section{Availability of data and materials}

355 The datasets obtained during this study are available from the corresponding author on reasonable 356 request.

357 Author contributions

358 All authors are contributed to designing the study. SYG, ECG, and FI are contributed to the whole 359 experiments, KUA and GV helped partially on experiments. KUA, SYG, and GV were contributed 360 to analyzing response surface methodology. KUA was the major contributor in writing the 361 manuscript, while all authors were contributed to writing, revising, and finalizing the manuscript. 362 All authors approved the final manuscript. 


\section{References}

364 Ao, X., Sun, W., Li, S., Yang, C., Li, C., and Lu, Z. (2019). Degradation of tetracycline by medium

Basturk, I., Varank, G., Murat Hocaoglu, S., and Yazici Guvenc, S. (2020). Medical laboratory wastewater treatment by electro-fenton process: Modeling and optimization using central composite design. Water Environ. Res., wer.1433. doi:10.1002/wer.1433.

Bi, W., Wu, Y., and Dong, W. (2020). The degradation of oxytetracycline with low concentration of persulfate sodium motivated by copper sulphate under simulated solar light. Chem. Eng. J. 393, 122782. doi:10.1016/j.cej.2019.122782.

Can-Guven, E., Guvenc, S. Y., Kavan, N., and Varank, G. (2020). Paper mill wastewater treatment by $\mathrm{Fe} 2+$ and heat-activated persulfate oxidation: Process modeling and optimization. Environ. Prog. Sustain. Energy. doi:10.1002/ep.13508.

Cherifi, Y., Addad, A., Vezin, H., Barras, A., Ouddane, B., Chaouchi, A., et al. (2019). PMS activation using reduced graphene oxide under sonication: Efficient metal-free catalytic system for the degradation of rhodamine $\mathrm{B}$, bisphenol A, and tetracycline. Ultrason. Sonochem. 52, 164-175. doi:10.1016/j.ultsonch.2018.11.012.

Cuerda-Correa, E. M., Alexandre-Franco, M. F., and Fernández-González, C. (2020). Advanced oxidation processes for the removal of antibiotics from water. An overview. Water (Switzerland) 12, 102. doi:10.3390/w12010102.

Espíndola, J. C., Cristóvão, R. O., Mendes, A., Boaventura, R. A. R., and Vilar, V. J. P. (2019). Photocatalytic membrane reactor performance towards oxytetracycline removal from synthetic and real matrices: Suspended vs immobilized TiO2-P25. Chem. Eng. J. 378, 122114. doi:10.1016/j.cej.2019.122114.

Genc, N., Durna, E., and Kayapinar Cicigun, H. K. (2020). Response Surface Modeling and Optimization of Microwave-Activated Persulfate Oxidation of Olive Oil Mill Wastewater. 
Han, C. H., Park, H. D., Kim, S. B., Yargeau, V., Choi, J. W., Lee, S. H., et al. (2020). Oxidation of tetracycline and oxytetracycline for the photo-Fenton process: Their transformation products and toxicity assessment. Water Res. 172, 115514. doi:10.1016/j.watres.2020.115514.

Ji, Y., Shi, Y., Dong, W., Wen, X., Jiang, M., and Lu, J. (2016). Thermo-activated persulfate oxidation system for tetracycline antibiotics degradation in aqueous solution. Chem. Eng. J. 298, 225-233. doi:10.1016/j.cej.2016.04.028.

398

399

400

401

402

403

404

405

406

407

408

409

410

Kumar Subramani, A., Rani, P., Wang, P. H., Chen, B. Y., Mohan, S., and Chang, C. T. (2019). Performance assessment of the combined treatment for oxytetracycline antibiotics removal by sonocatalysis and degradation using Pseudomonas aeruginosa. J. Environ. Chem. Eng. 7, 103215. doi:10.1016/j.jece.2019.103215.

Lai, W., Xie, G., Dai, R., Kuang, C., Xu, Y., Pan, Z., et al. (2020). Kinetics and mechanisms of oxytetracycline degradation in an electro-Fenton system with a modified graphite felt cathode. J. Environ. Manage. 257, 109968. doi:10.1016/j.jenvman.2019.109968.

Li, K., Yediler, A., Yang, M., Schulte-Hostede, S., and Wong, M. H. (2008). Ozonation of oxytetracycline and toxicological assessment of its oxidation by-products. Chemosphere 72, 473-478. doi:10.1016/j.chemosphere.2008.02.008.

Li, Z., Sun, Y., Yang, Y., Han, Y., Wang, T., Chen, J., et al. (2020). Comparing biochar- and bentonite-supported Fe-based catalysts for selective degradation of antibiotics: Mechanisms and pathway. Environ. Res. 183, 109156. doi:10.1016/j.envres.2020.109156.

Liu, D., Li, M., Li, X., Ren, F., Sun, P., and Zhou, L. (2020). Core-shell Zn/Co MOFs derived Co3O4/CNTs as an efficient magnetic heterogeneous catalyst for persulfate activation and oxytetracycline degradation. Chem. Eng. J. 387, 124008. doi:10.1016/j.cej.2019.124008.

Liu, Y., He, X., Duan, X., Fu, Y., Fatta-Kassinos, D., and Dionysiou, D. D. (2016a). Significant role of UV and carbonate radical on the degradation of oxytetracycline in UV-AOPs: Kinetics and mechanism. Water Res. 95, 195-204. doi:10.1016/j.watres.2016.03.011. 
417 Liu, Y., He, X., Fu, Y., and Dionysiou, D. D. (2016b). Kinetics and mechanism investigation on the destruction of oxytetracycline by UV-254 nm activation of persulfate. J. Hazard. Mater. 305, 229-239. doi:10.1016/j.jhazmat.2015.11.043.

Majumdar, A., and Pal, A. (2020). Optimized synthesis of Bi4NbO8Cl perovskite nanosheets for enhanced visible light assisted photocatalytic degradation of tetracycline antibiotics. $J$. Environ. Chem. Eng. 8, 103645. doi:10.1016/j.jece.2019.103645.

Malakotian, M., Asadzadeh, S. N., Khatami, M., Ahmadian, M., Heidari, M. R., Karimi, P., et al. (2019). Protocol encompassing ultrasound/Fe3O4 nanoparticles/persulfate for the removal of tetracycline antibiotics from aqueous environments. Clean Technol. Environ. Policy 21, 1665-1674. doi:10.1007/s10098-019-01733-w.

Pan, Y., Zhang, Y., Zhou, M., Cai, J., and Tian, Y. (2019). Enhanced removal of emerging contaminants using persulfate activated by UV and pre-magnetized Fe0. Chem. Eng. J. 361, 908-918. doi:10.1016/j.cej.2018.12.135.

Rahdar, S., Pal, K., Mohammadi, L., Rahdar, A., Goharniya, Y., Samani, S., et al. (2020). Response surface methodology for the removal of nitrate ions by adsorption onto copper

Ulucan-Altuntas, K., and Debik, E. (2020). Dechlorination of dichlorodiphenyltrichloroethane (DDT) by Fe/Pd bimetallic nanoparticles: Comparison with nZVI, degradation mechanism, and pathways. Front. Environ. Sci. Eng. 14. doi:10.1007/s11783-019-1196-2.

Ulucan-Altuntas, K., and Ilhan, F. (2018). Enhancing Biodegradability of Textile Wastewater by Ozonation Processes: Optimization with Response Surface Methodology. Ozone Sci. Eng. doi:10.1080/01919512.2018.1474339.

Varank, G. (2020). Leachate nanofiltration concentrate treatment by advanced electrochemical processes to achieve zero waste discharge: modeling and optimization. doi:10.5004/dwt.2020.26361.

442 Wang, J., and Wang, S. (2018). Activation of persulfate (PS) and peroxymonosulfate (PMS) and 443 application for the degradation of emerging contaminants. Chem. Eng. J. 334, 1502-1517. 
445 Yan, H., Luo, M., Chen, Q., Jeong, T., Zhang, J., and Wang, L. (2020). Efficacy and Mechanism 446 of Chemical-free VUV/UV Process for Oxytetracycline Degradation: Continuous-flow 447 Experiment and CFD Modeling. Chem. Eng. J. Adv., 100059. 448 doi:10.1016/j.ceja.2020.100059.

449 Zhang, F., Yue, Q., Gao, Y., Gao, B., Xu, X., Ren, Z., et al. (2017). Application for oxytetracycline 450 wastewater pretreatment by Fenton iron mud based cathodic-anodic-electrolysis ceramic 451 granular fillers. Chemosphere 182, 483-490. doi:10.1016/j.chemosphere.2017.05.058. 
Figures

a.

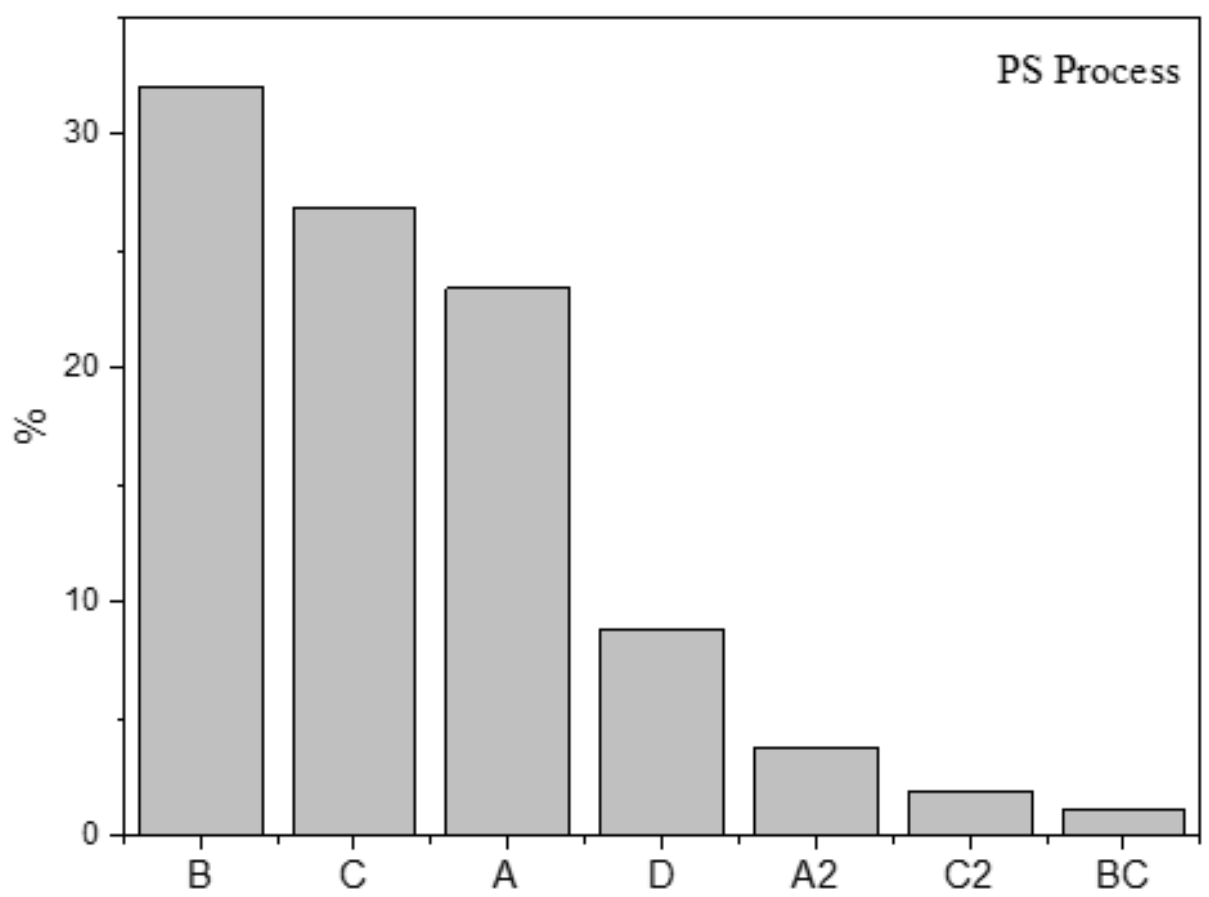

b.

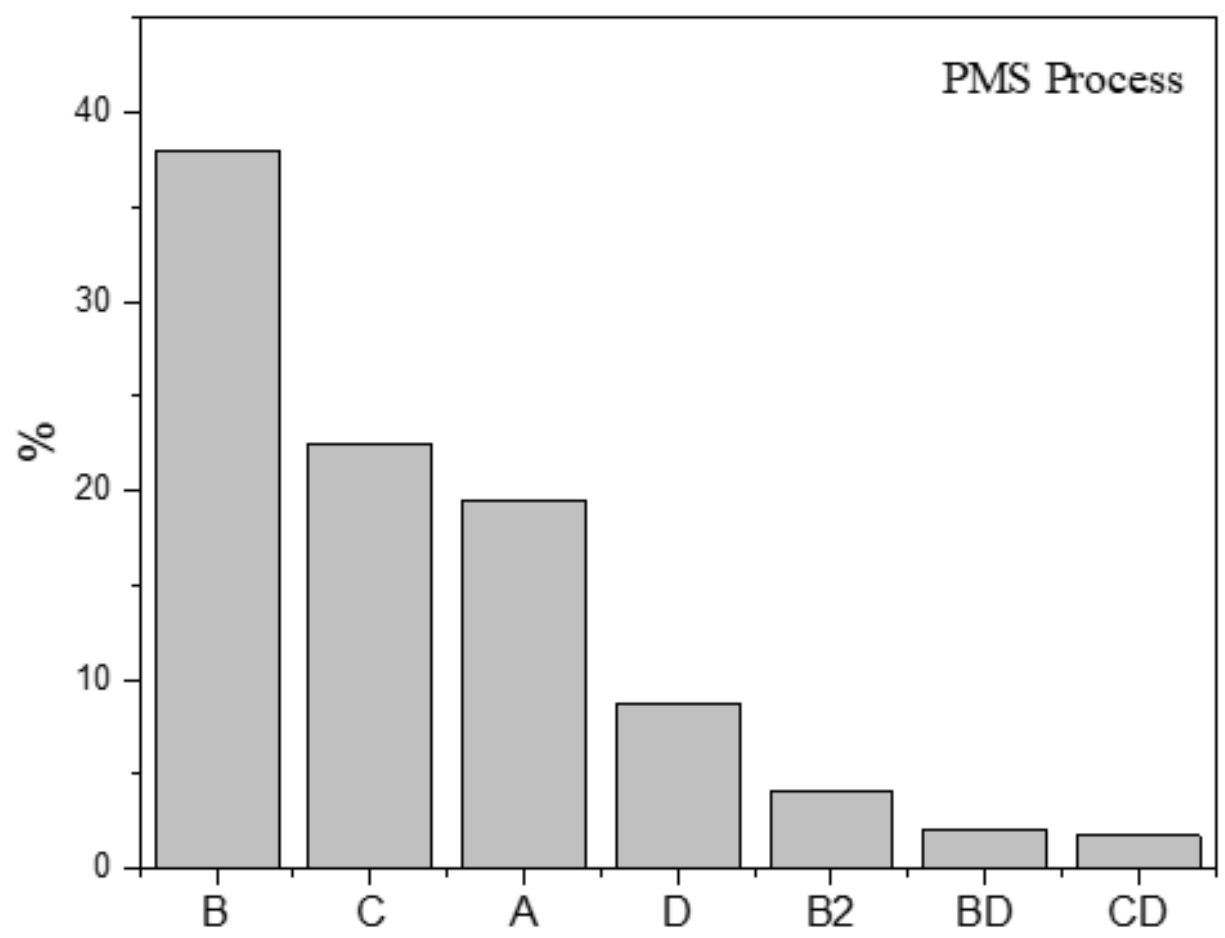

Figure 1

Pareto charts for (a) PS process and (b) PMS process 
a.

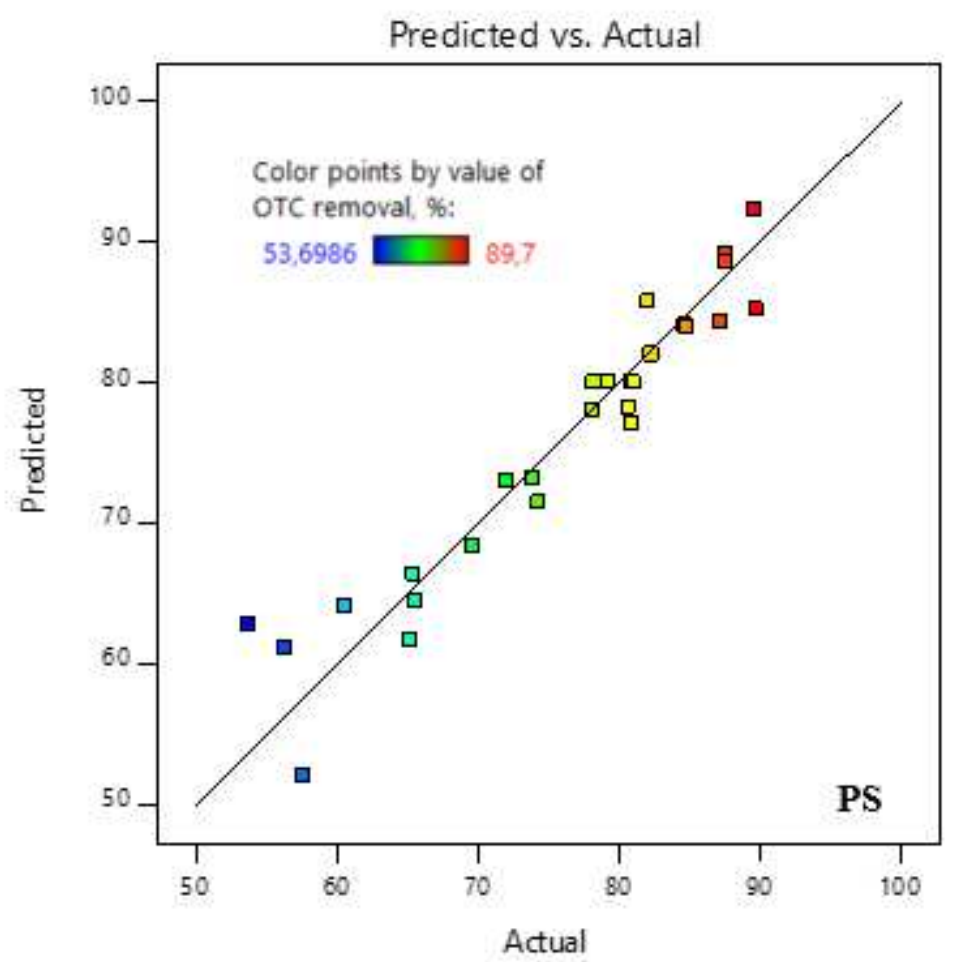

b.

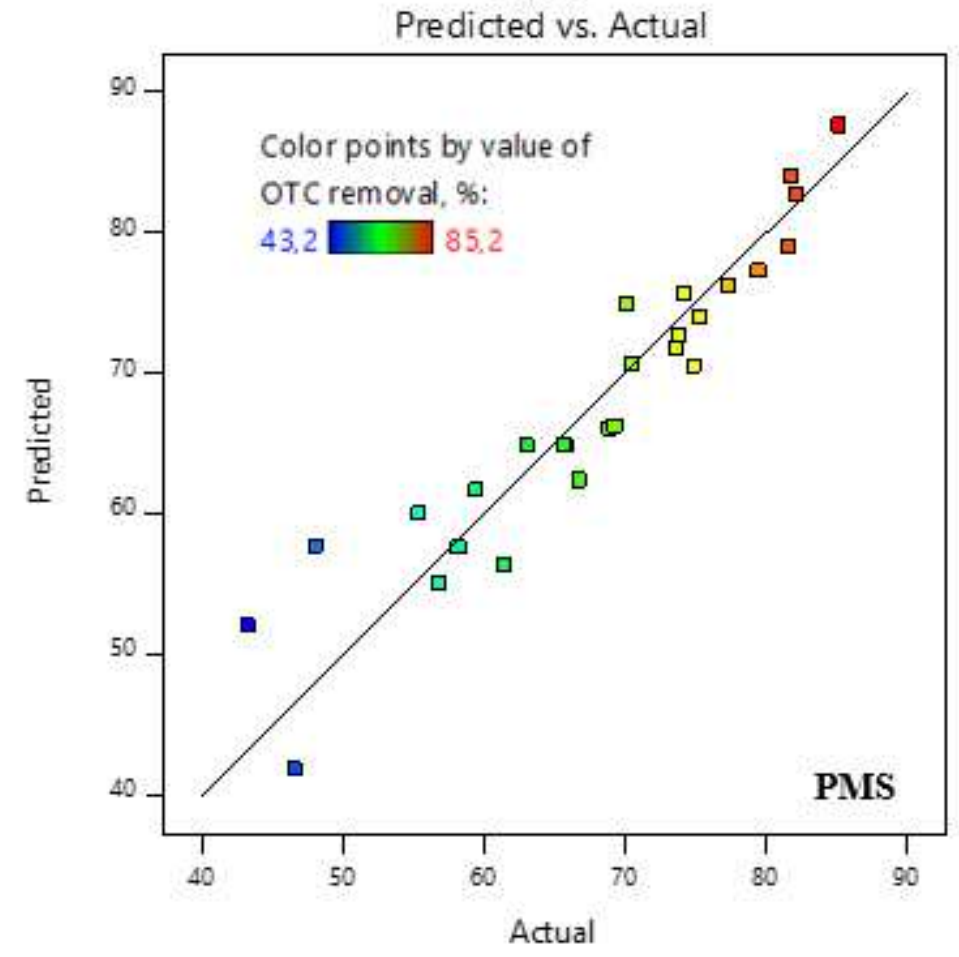

Figure 2

Actual vs. predicted values for (a) PS and (b) PMS oxidation 


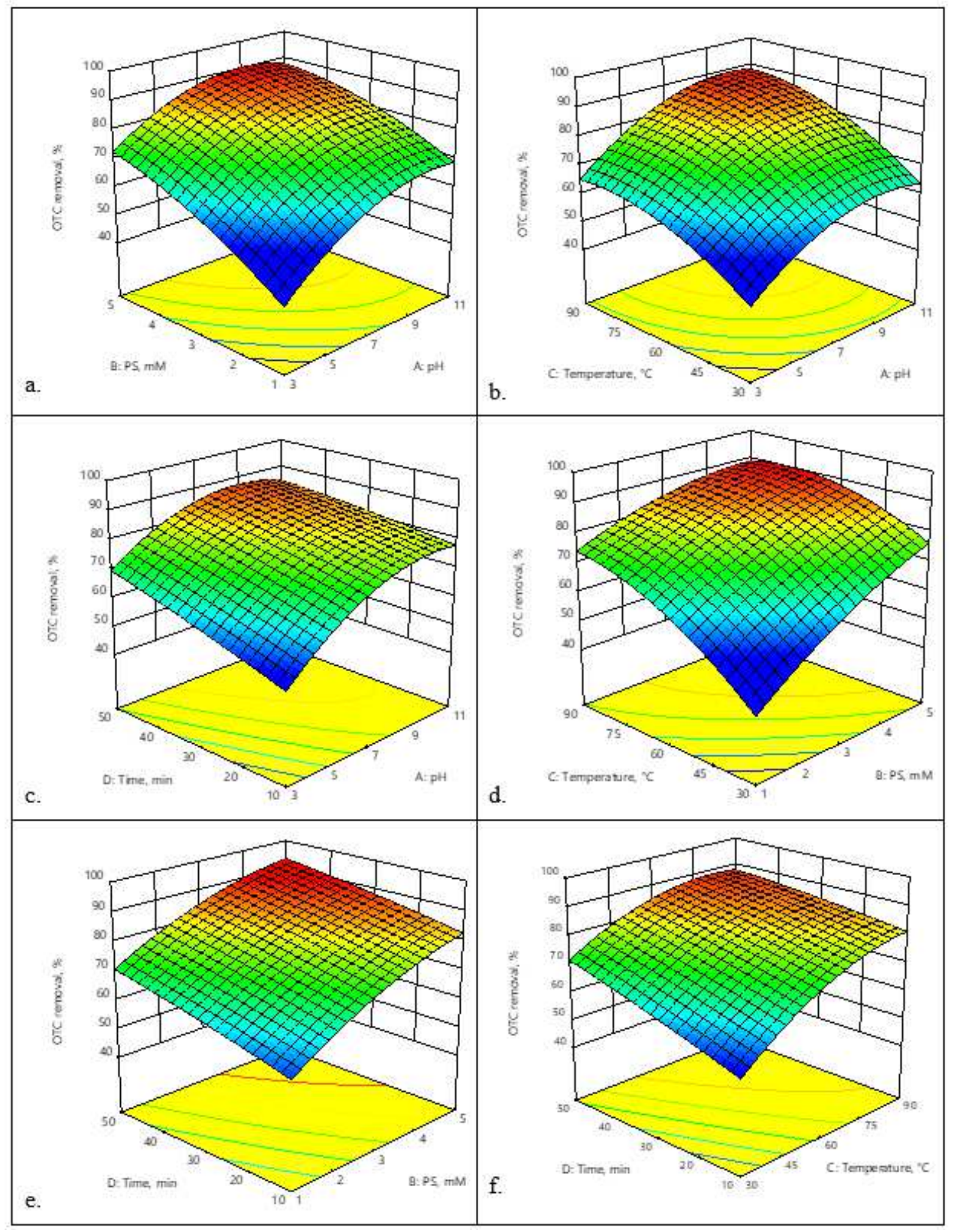

\section{Figure 3}

3D plots for heat activated-PS oxidation 


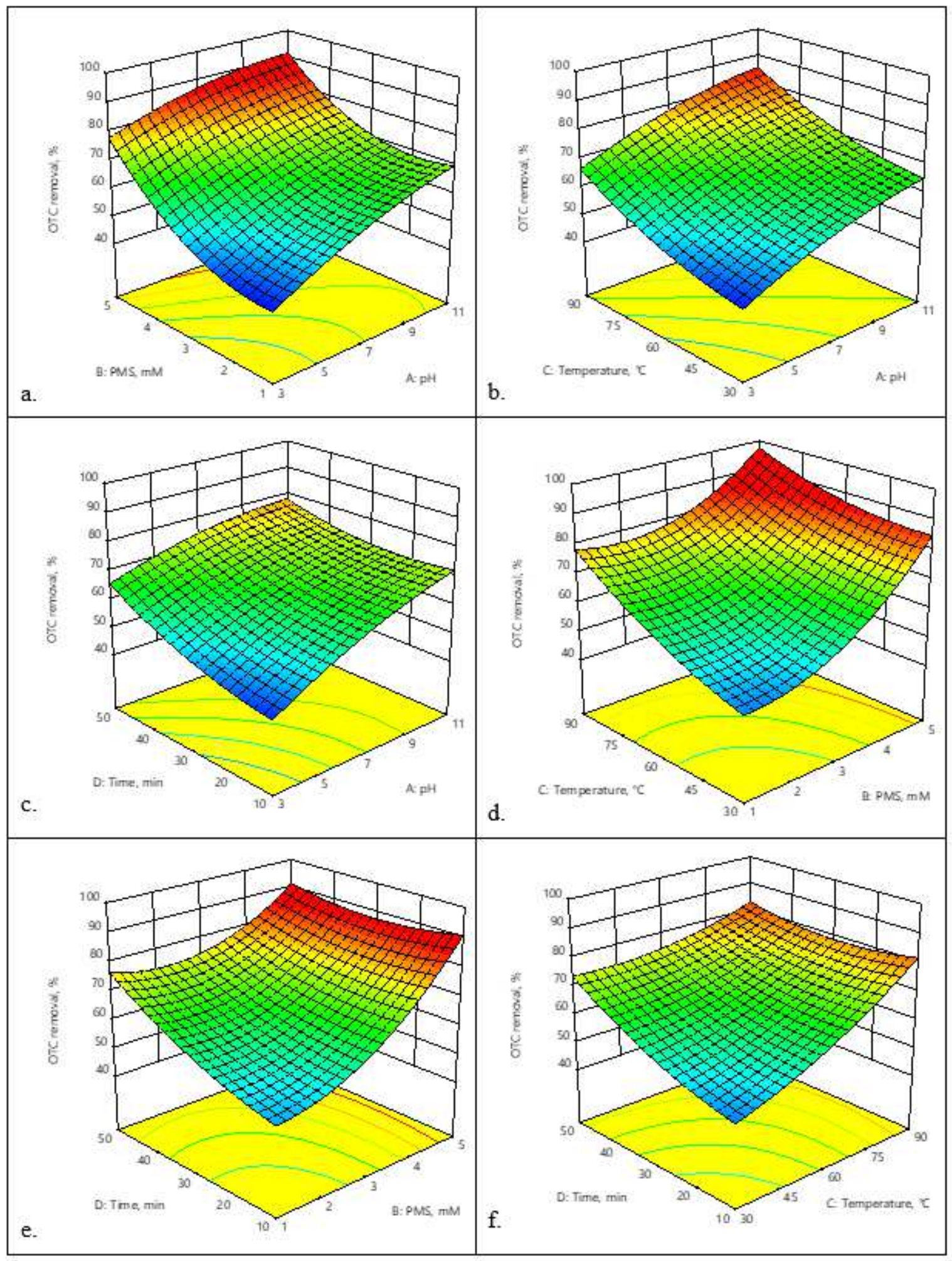

Figure 4

3D plots for heat activated-PS oxidation 


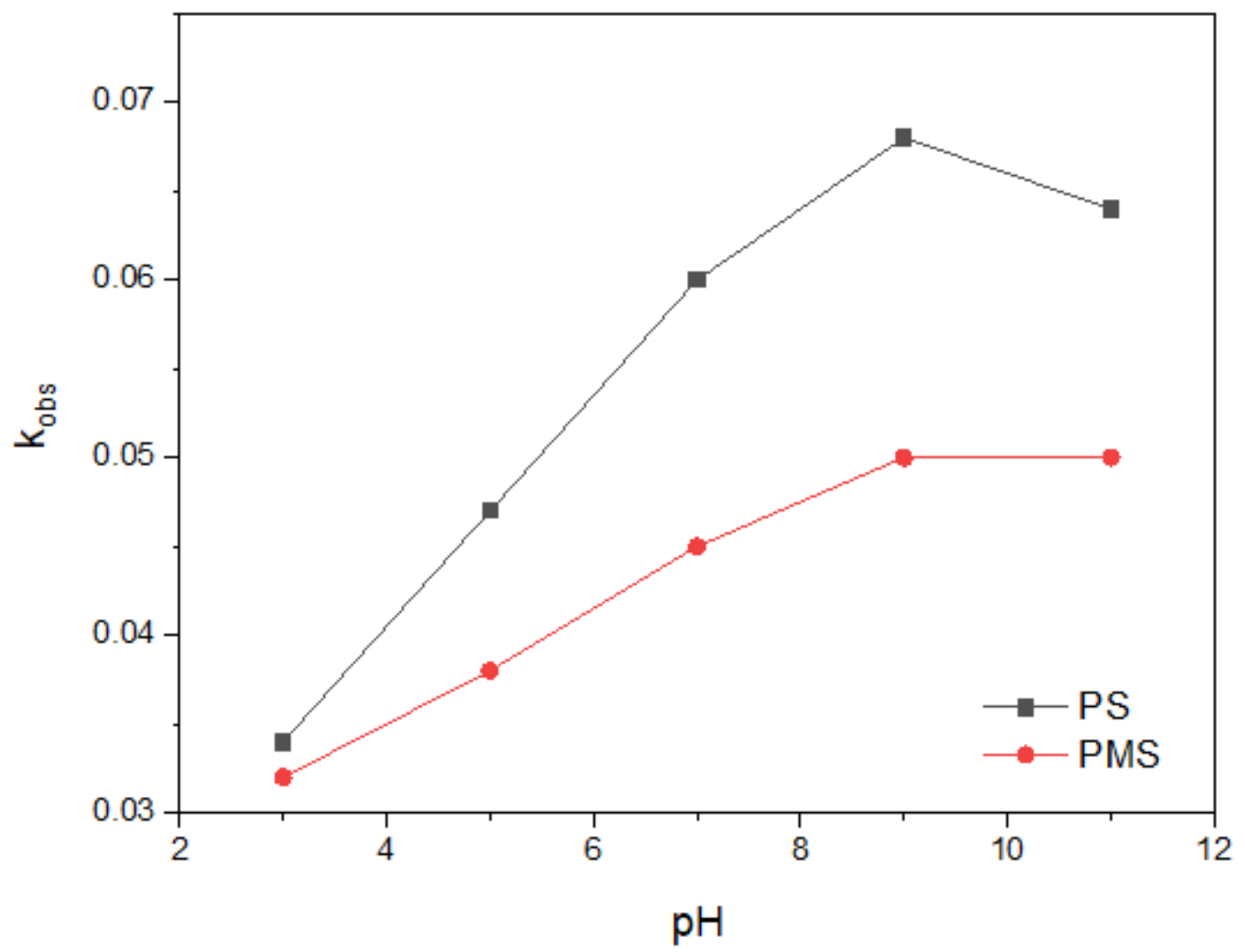

Figure 5

kt values at different $\mathrm{pH}$ values with Ps and PMS processes 
a.

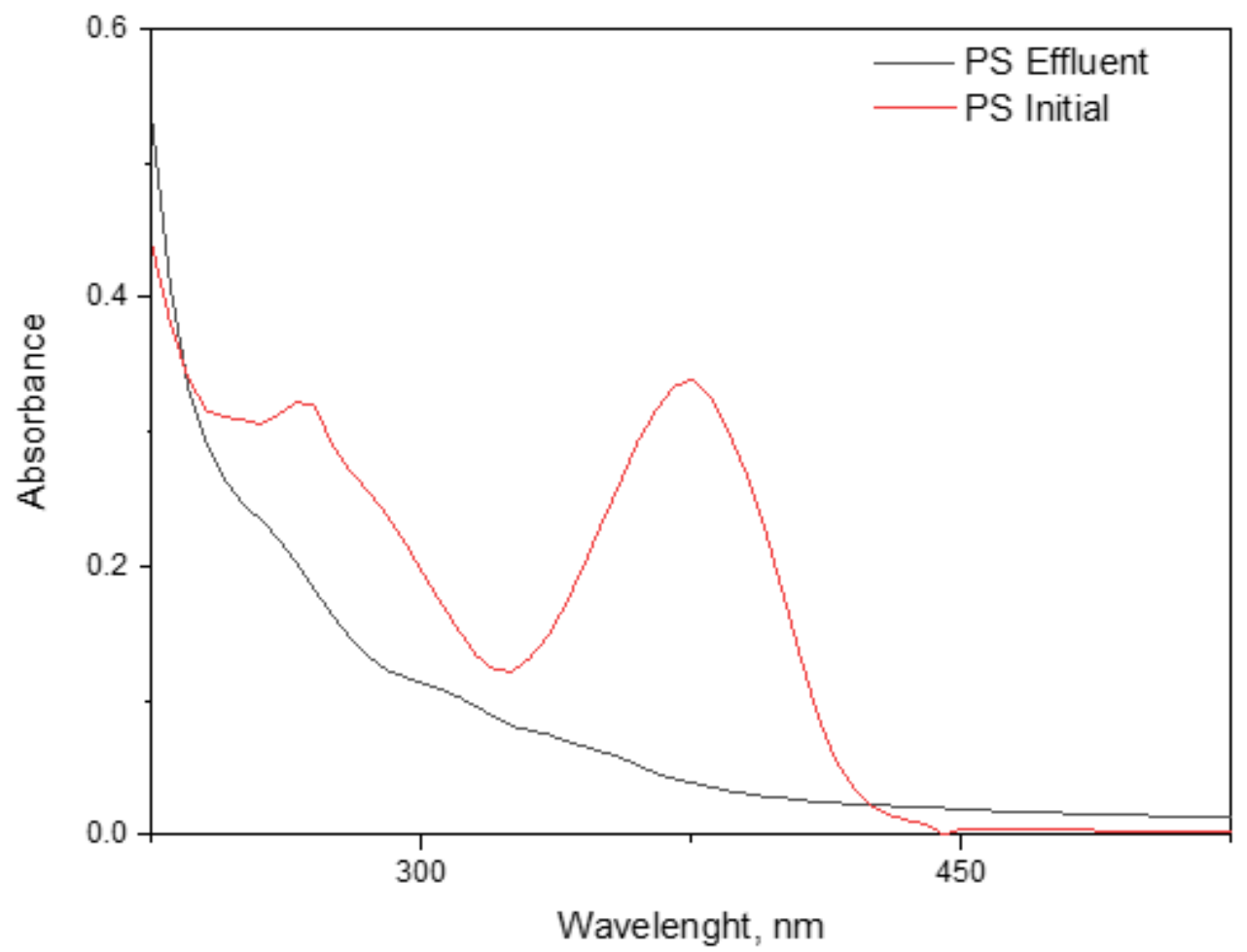

b.

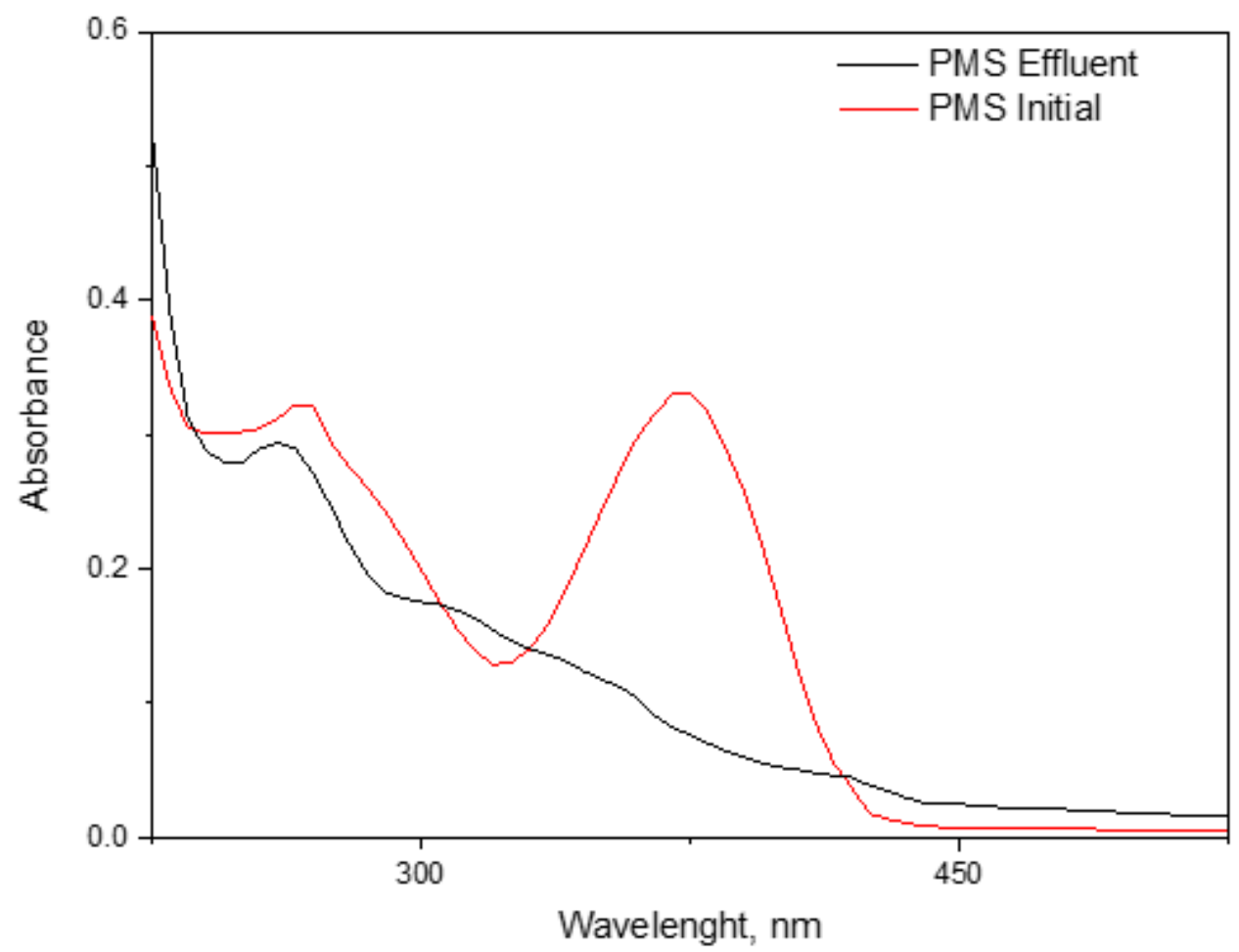

Figure 6

UV-vis spectrum of OTC samples before and after treatment by (a) PS and (b) PMS processes 